Woith, H., Petersen, G., Hainzl, S., Dahm, T. (2018):

Review: Can Animals Predict Earthquakes? - Bulletin of the Seismological Society of America, 108, 3A, 1031-1045.

https://doi.org/10.1785/0120170313 


\title{
Can animals predict earthquakes?
}

Heiko Woith $^{1 *}$, Gesa M. Petersen ${ }^{1,2}$, Sebastian Hainzl ${ }^{1}$, Torsten Dahm ${ }^{1,2}$

${ }^{1}$ GFZ German Research Centre for Geosciences, Potsdam, Germany

${ }^{2}$ also at: Institute of Earth and Environmental Sciences, University of Potsdam, Golm, Germany

\begin{abstract}
In public perception abnormal animal behavior is widely assumed to be a potential earthquake precursor, in strong contrast to the viewpoint in natural sciences. Proponents of earthquake prediction through animals claim that animals feel and react abnormal to small changes in environmental and physico-chemical parameters which are related to the earthquake preparation process. In seismology, however, observational evidence for changes of physical parameters before earthquakes is very weak.

In this study we reviewed 180 publications on abnormal animal behavior before earthquakes, and analyze and discuss them with respect to (i) magnitude-distance relations, (ii) foreshock activity, and (iii) the quality and length of the published observations. More than 700 records of claimed animal precursors related to 160 earthquakes are reviewed with unusual behavior of more than 130 species. The precursor time ranges from months to seconds prior to the earthquakes, and the distances from few to hundreds of kilometers. However, only 14 time series were published, while all other records are single observations. The time series are often short (the longest is 1 year), or only small excerpts of the full data set are shown. The probability density of foreshocks and the occurrence of animal precursors are strikingly similar, suggesting that at least part of the reported animal precursors are in fact related to foreshocks. Another major difficulty for a systematic and statistical analysis is the high diversity of data, which are often only anecdotal and retrospective. The study clearly demonstrates strong weaknesses or even deficits in many of the published reports on possible abnormal animal behavior. In order to improve the research on precursors, we suggest a scheme of yes and no questions to be assessed to ensure the quality of such claims.
\end{abstract}

\section{Introduction}

Abnormal behavior of animals before earthquakes has been reported many times. Examples are provided in recent papers on the 2010 Darfield, New Zealand and 2009 L'Aquila, Italy, major earthquakes (Fidani, 2013; Grant et al., 2011; Whitehead and Ulusoy, 2013). However, it is questionable whether such abnormal behavior was causally related to the nucleation process of the upcoming earthquake. The predictive power of such observations depends on whether it can be classified as an anomaly, a precursor, or a predictor. An anomaly is defined as an unexpected

\footnotetext{
* Corresponding author:

Heiko Woith

GFZ German Research Centre for Geosciences

Helmholtzstr. 7

14467 Potsdam, Germany

Tel. +49 (331) 2881234

E-mail: heiko.woith@gfz-potsdam.de
} 
value of an observable which exceeds some threshold value associated to a particular quantile of the recorded values. Such an anomaly of an observable might occur simply by chance before an earthquake. In contrast, a precursor is an anomaly which is causally related to the earthquake preparation process. However, a precursor such as seismic foreshocks might as well occur without a major earthquake occurrence. The occurrence of a precursor usually does not represent a one-to-one relation to an upcoming earthquake. In contrast, the occurrence of a predictor would represent a deterministic relation to a subsequent earthquake. The judgement whether or not the recording of animal behavior can be useful for earthquake forecasting thus depends on the classification of the observed abnormal behavior (the anomaly) as precursor or predictor.

Every study of possible earthquake precursor signals or predictors must consider the inherently random nature of earthquake occurrences. The frequency-size distribution follows a well-defined empirical relation (Gutenberg-Richter relation) which states that the number of events in a region and given time period with one magnitude smaller than the studied one is about 10 times larger. In periods without large magnitude earthquakes (mainshocks), the average number of events within a given magnitude and time interval is usually constant. However, the stresses induced by mainshock ruptures trigger additional earthquakes, so-called aftershocks, clustered within a distance of several lengths of the mainshock rupture during a period of months to years. Typically about half of the events in earthquake catalogs are aftershocks. Any study of possible precursors or predictors must therefore consider the specific statistical behavior of seismicity and implement a rigorous statistical testing against a random coincidence. Furthermore, abnormal behavior might be related to foreshocks, which occur before some of the main shocks. Abnormal animal behavior is only one out of many different suggestions for earthquake precursors and predictors. As detailed in section Earthquake prediction research, specific types of non-seismic precursors were discussed e.g. for electromagnetic signals, ground deformation, hydrogeological phenomena, radon emissions, and changes of the ionosphere. Seismicity patterns have also been claimed to have predictive power, such as accelerated seismic moment release (Varnes, 1989), foreshock activity (Mogi, 1986), b-value decrease (Smith, 1981), and precursory seismic quiescence (Wyss and Habermann, 1988). However, none of these observations have been verified so far to be a predictor of upcoming major earthquakes.

Because of ongoing problems to assess and verify claims of earthquake predictors, an international Collaboratory for the Study of Earthquake Predictability (CSEP) has been formed during the last decade in order to perform fully prospective and comparative tests of proposed forecast models (Jordan, 2006; Schorlemmer et al., 2007). Within the different CSEP testing centers, developed (regional and global) earthquake models run automatically based on an authorized input data stream which allows an independent and systematic evaluation of the model performance (Schorlemmer and Gerstenberger, 2007; Tsuruoka et al., 2012). This approach works successfully for models based on seismological input data, in particular earthquake catalogs, which are routinely produced by independent seismological services. However, other input information such as animal behavior is not available in the same manner and thus a CSEP-type approach cannot be simply applied. Nevertheless minimum requirements of documentation, data, parameters, and analysis can be established which are necessary for any scientific evaluation. The aim of this study is to provide an overview of available, published data and analysis of animal-related earthquake precursors in order to assess the potential for any systematic evaluation and testing. 
To clarify the relation of these studies with our physical knowledge and past studies of other predictors, we firstly provide in section Review of earthquake processes and prediction research brief reviews of our state-of-the-art knowledge of the processes associated with earthquake ruptures and the history of (failed) earthquake prediction research. Then, the results of our data survey for anomalous animal behavior are presented in the section Reports of anomalous animal behavior related to earthquakes and in the Discussion. Because most of the presently available studies of animal behavior are shown to fail the requirements for any statistical evaluation (section Summary), we finally propose some general recommendations for upcoming experimental studies of animal behavior in order to provide a basis for future systematic testing of the forecast ability of animal-based earthquake models. An in-depth discussion of the physical mechanisms proposed to explain abnormal behavior of various animal species (see e.g. Buskirk et al., 1981; Kirschvink et al., 2010) is beyond the scope of this review. A brief overview of the proposed mechanisms and animal species is provided in the Supplementary Material.

\section{Review of earthquake processes and prediction research}

\subsection{Earthquake process}

An earthquake is commonly perceived by the strong ground shaking as a result from the sudden failure and rupture of rocks. Scientifically, we distinguish between the source process of the rupture at depth, i.e. the nucleation or initiation phase and the propagation of slip between two blocks of rock along a fault, and the wave propagation, ground motion and other measures observed at the surface in some distance from the earthquake fault. The rupture propagation and slip at depth is mainly driven by elastic shear stresses, which are inherently present in most rock volumes.

The rupture process is triggered if shear stresses locally exceed the strength of the fault, or if high pore pressure locally reduces the effective normal stress between the blocks (King et al., 1994). Additionally, stress corrosion or other processes may weaken rock strength and explain the nucleation of rupture (Das and Scholz, 1983; Kerr, 2011; Ohnaka, 1992). For some large earthquakes precursory slip over weeks or month have been indicated by seismic and geodetic monitoring (Bouchon et al., 2011, 2013; Kato et al., 2012; Schurr et al., 2014), but also questioned by Hardebeck et al. (2008). However, such so-called nucleation phases are not always recorded and often rupture nucleates without any precursors.

Ruptures of the largest earthquakes with magnitudes $M>8$ reach several hundred kilometers in length and sample the full depth of the seismogenic crust or plate interface. The co-seismic slip of such ruptures can reach more than $10 \mathrm{~m}$. An M 6 earthquake may have a rupture dimension of still $\approx 17 \mathrm{~km}$ (Wyss, 1979; Wells and Coppersmith, 1995) and a slip of $\approx 0.3 \mathrm{~m}$, while an M 4 event will cover a plane dimension of only $\approx 2 \mathrm{~km}$ and a slip of $\approx 0.01 \mathrm{~m}$ (according to empirical estimates of Papazachos, 2004). Any precursory slip phase, if it exists, affects a much smaller segment or asperity on the fault plane. As indicated by theoretical and empirical scaling relations, the third power of the critical size of the slow-slip nucleation phase of an earthquake is proportional to the seismic moment of the earthquake (Ohnaka, 2000, 2013), by $\mathrm{M}_{0} \approx 0.810^{9}$ $\left(2 L_{c}\right)^{3}$, where $L_{c}$ (half-length of the nucleation zone) is given in $\mathrm{m}$. Thus, the corresponding 
magnitude of the slow-slip nucleation phase is roughly 2 magnitude units smaller than the magnitude of the main-shock.

The static displacement associated with slip on the fault attenuates quickly with distance $\mathrm{r}$ according to $\sim \mathrm{r}^{-2}$ or faster. Therefore, precursory phases, if they exist, are very hard to be detected by any sensor if it is placed a few kilometers from the fault. However, seismologists have discussed other potential measures resulting indirectly from small precursory processes at depth, including (1) the effect of the tiny strain or stress changes on the width of micro-cracks, which may influence the intrinsic anisotropy and elastic velocity of rocks (Crampin and Yuan 2014), the diffuse degassing at the surface (Richon et al., 2003) or the flow and head change of fluids in superficial cracks (Orihara et al., 2014), and (2) the possible change in background seismicity as a result of stress changes induced by preparatory phases (Schurr et al., 2014). However, stress changes associated with Earth tides, meteoric or hydrological pressure systems or temperature variations are often of a similar size as expected for pre-seismic slip and both, (1) and (2), have not been successful as a predictor of an upcoming earthquake rupture.

\subsection{Earthquake prediction research}

A historical view of concepts about earthquakes, earthquake precursors, and earthquake prediction research was compiled by Martinelli (2000). Reviews on the earthquake precursors in general were provided by Cicerone et al. (2009), Kossobokov (2013), Mogi (1986), and Turcotte (1991). Specific types of precursors were discussed for electromagnetic field strength variation in the atmosphere (Park et al., 1993; Uyeda et al., 2009), for hydrogeological phenomena in the underground (Hartmann and Levy, 2005; Ingebritsen and Manga, 2014; Roeloffs, 1988; Thomas, 1988; Toutain and Baubron, 1999), and for radon emissions at the Earth surface (Woith, 2015).

In the early seventies of the last century scientists were quite enthusiastic to possibly solve the earthquake prediction problem within the near future. Potential precursors had been suggested (Rikitake, 1975), several models for earthquake prediction were developed (Aggarwal et al., 1973; Nur, 1972; Scholz et al., 1973), and research projects were launched in many countries aimed to predict earthquakes. In Liaoning in eastern China, the city of Haicheng was evacuated 10 hours before a major M 7.3 earthquake hit the region on 4 February 1975 (Wang et al., 2006; Wyss and $\mathrm{Wu}, 2014)$. The authorities were alarmed by an unusual increase of seismicity, as well as some other potential anomalies.

In California the so-called Parkfield project (Bakun and Lindh, 1985) started in 1981 to observe the preparatory phase of an M 6 earthquake at a segment of the San Andreas Fault, which was indicated from historical records to be apparently overdue to rupture. An official earthquake prediction had been issued by the USGS in 1985 that a magnitude 6 event should have occurred with a 95\% probability before the end of 1993 (Michael and Langbein, 1993; Roeloffs and Langbein, 1994). However, the anticipated event only occurred in 2004 and no precursors had been observed despite the extensive near-field instrumentation (Bakun et al., 2005; Jackson and Kagan, 2006; Langbein et al., 2005).

During the last decade several claims were made that earthquakes could be predicted from changes in the ionosphere as tracked from satellites (Ouzounov et al., 2006), for instance related to increased radon emissions into the atmosphere and ionosphere before an earthquake (Pulinets 
and Ouzounov, 2011). Nevertheless, ground truth measurements for increased radon release in context with the claimed ionospheric anomalies are still lacking, and a rigorous statistical relationship between the ionospheric total electron content changes and the occurrences of $M \geq 6.0$ global earthquakes during 2000-2014 was not confirmed (Thomas et al., 2017).

After more and more in-depth studies and mis-estimations of various precursors, the scientific prospects were assessed lower and lower, and Robert J. Geller concluded already 20 years ago that a deterministic earthquake prediction is inherently impossible (Geller, 1991, 1997; Geller et al., 1997) due to non-linear processes highly sensitive to details of the state of the crust. Others disputed some of Geller's underlying key assumptions and provided a more differentiated view towards the future of deterministic predictions (Sykes et al., 1999; Wyss, 2001).

Despite the chastening perspectives of deterministic earthquake predictions the scientific field of time-dependent, probabilistic forecasting of earthquakes has recently been developed into operational systems (see Jordan et al. (2011) for a compilation), even if the prospective testing of such probabilistic forecasts is still very difficult from the short times of observations.

\section{Reports of anomalous animal behavior related to earthquakes}

\subsection{Public perception}

In public perception, abnormal animal behavior is widely recognized as a potential earthquake precursor. Searching the web on January 2018 with google for the term "earthquake precursor" provided 106,000 results. By adding "animal” to the search term, the number decreased to 28,000 (about 20\%). The actual numbers may change with the improvement of search algorithms, possibly also user-specific. Using the same combination in "Web of Science" provided 2327 results of which 22 (about 1\%) are related to animal behavior. This discrepancy between scientific research and the public perception shows that speculations and the craving for sensations exists on the one hand and complete rejection results on the other hand.

The apparent overrating of animal behavior in relation to earthquakes in the social media becomes also obvious when asking directly the population affected by an earthquake. Since 2002, the Royal Observatory of Belgium is collecting web-based questionnaires on felt reports after major earthquakes. Since 2010, this system is shared with the earthquake observatory at Bensberg, University of Cologne, Germany (Lecocq et al., 2009; van Noten et al., 2017). Applicants have the possibility to report their observations in a comment field. Out of 32,258 filled reports, only 1.5\% (499) reported unusual behaviors of dogs, cats, birds or cows (Thomas Lecocq, Pers. Communication). These $1.5 \%$ reports include also trivial statements as for instance „the situation was unusual because my dog did not behave unusual before the earthquake”. In the nineteenth century the Prussian administration systematically conducted surveys similar to present-day macroseismic questionnaires to collect information about earthquakes. The early versions (starting in 1828) also contained questions related to animal behavior. Interestingly, these questions had been removed in 1877 after evaluating their usefulness (Knuts et al., 2017). 


\subsection{Review of observations and experiments: Case studies}

Here, we report briefly case studies to exemplify typical weaknesses related to (i) unclear observations, (ii) lack of environmental monitoring, (iii) poor statistics and/or short time series, and (iv) unrobust interpretations.

Often, reports and claims were based on anecdotal and unproved observations. For instance, after the M 9.1 Sumatra megathrust earthquake of 26 December 2004 and the devastating tsunami in the Indian Ocean numerous reports were distributed by the media about elephants fleeing to higher grounds. These were taken up in several claims on a possible use of elephants as early warning sensors. For the same earthquake the behavior of two satellite-collared Asian elephants could be tracked during the Indonesian tsunami. Although both elephants ranged close to the tsunami impact area in Sri Lanka, the data did not show any indication of a "sixth sense" or unusual behavior allowing an early detection of the approaching tsunami (Garstang, 2009; Wikramanayake et al., 2006).

Retrospective studies often lack observations of environmental parameters of interest. For instance, based on a retrospective study of abnormal animal behavior Lott et al. (1979) concluded from 50 interviews with persons in the epicentral region that the M 4.7 Willits earthquake (22 November 1977) in California had been preceded by abnormal animal behavior, without presenting a consistent model. McClellan (1980) pointed out that 3 external environmental factors might have influenced the animal behavior at the time of the Willits earthquake, namely (i) heavy rainfall and flooding, (ii) large barometric pressure variations, and (iii) enhanced solar-flare cosmic radiation.

A systematic monitoring of animal behavior in the field has been performed in several studies, either by coincidence during the time of a close-by earthquake or for a longer period to hope to catch an event. Often, the data analysis is poor, or only selected subsets of data are presented, or rare observations are not reproducible. Berberich et al. (2013) suggest that redwood ants build their mounds preferable on faults (Berberich and Schreiber, 2013) and show abnormal behavior before small earthquakes in the Eifel region, Germany. The ants are continuously monitored by video cameras with color and infrared sensors. Eight different types of behavior (from absent to high activity) are classified both, manually and automatically. Different types of environmental parameters were monitored as well as the appearance of predators. Berberich and Schreiber (2013) presented only 22 days out of the total monitoring period of 3 years to demonstrate that the nocturnal rest phase and the daily activity were suppressed hours before a M 3.2 earthquake which occurred at a distance of $40 \mathrm{~km}$. Apostol et al. (2016) could not reproduce the observations of Berberich and Schreiber (2013) during a two-year-study in Romania. Lighton and Duncan (2005) studied the effect of the Landers M 7.4 earthquake in the Mojave Desert, USA on trail dynamics and aerobic catabolism of the ant Messor pergandei and concluded that the earthquake had no effect on their behavior.

Grant and Halliday (2010) studied the activity of breeding amphibians (toads) in a lake about 75 km from the 6 April $2009 \mathrm{M}_{\mathrm{w}} 6.3$ earthquake in L'Aquila, Italy. During the annual breeding period in this part of Italy between end of March and beginning of April the toads typically migrate towards lakes. The authors claimed that the number of migrating toads changed prior to the earthquake. The daily number of male toads was counted along a $2.5 \mathrm{~km}$ transect, and was 
correlated with different data streams, as weather data (temperature, humidity, wind) at a station $15 \mathrm{~km}$ distant, to the number of days before and after the main shock, and to very low frequency electromagnetic signal perturbations (VLF) on an epicenter-crossing path between Sardinia and Moscow. The toad time series was 29 days (28 samples) and is characterized by some variation including three peaks of higher activity. The number of toads declined 5 days before the earthquake until 9 days after it. This period of unusual low activity is interrupted with a small local maximum of activity around full moon. From a multiple regression analysis the authors concluded that the number of toads is not related to any meteorological parameter. The authors suggest that the observed toad activity was related to the earthquake and its largest aftershocks, and may have been a reaction to the VLF perturbations. Although the potentially influencing meteorological parameters have been addressed statistically, this example demonstrates how questionable the analysis and interpretation of a short time series is, especially when the length of the anomaly is large with respect to the presented time series. In this case the toads were said to behave abnormal during nearly $50 \%$ (5 days before the earthquake +9 days after the mainshock $=14$ days of 29 days) of the observation time.

Systematic studies under controlled laboratory conditions are rare. Likely one of the first such experiments was performed by Hatai and Abe (1932), who studied catfish (Parasilurus asotus) in an aquarium connected to creek water. The researchers tried to disturb the catfish by knocking at the table below the aquarium three times a day. According to the study, the catfish ignored this trigger unless an earthquake followed within the next 6 to 8 hours. Using this approach, during seven months 149 of 178 (nearly 80\%) earthquakes were predicted. Apparently, predictions failed when the aquariums were disconnected from the flowing creek water. A careful review of the statistical approach demonstrates a problem. 80\% success rate sounds impressive, but it might have been just by chance. 178 earthquakes occurred during 210 days of observation time. Thus, at $85 \%$ of the observation days an earthquake might have occurred - unfortunately, no further information is available about the spatial and temporal occurrence of the events.

During the M 8.0 Wenchuan earthquake of 12 May 2008, Li et al. (2009) monitored locomotor activity and circadian rhythms of mice kept in constant darkness under stable temperature and humidity conditions in an isolated laboratory at $75 \mathrm{~km}$ epicentral distance. Locomotor activity of 8 mice was observed for 38 days in the frame of routine studies starting 18 days before the event. The original study design was not intended to find earthquake precursors, only a posteriori the data were re-investigated in the context of the earthquake. The mice were individually kept in cages equipped with running wheels with infrared switches attached to them. The activity quantified as wheel turns per day - decreased significantly during the time of the earthquake starting 3 days before and lasting until 3 days after the mainshock. The monitoring was not repeated for another earthquake. The authors could not present a plausible model for the change of mice behavior. They speculate about changes in the magnetic field, although the field variations were very small on the order of few nT. A data-wise less convincing, but otherwise similar case of mice behavior during the 1995 Kobe earthquake has been reported by Yokoi et al. (2003). 


\subsection{Statistical analysis}

All in all, 729 reports on abnormal animal behavior related to 160 earthquakes were statistically evaluated, based on 44 publications (table 1). Other publications deal with mechanisms, review data which had been used before, and/or contain cases which are so vaguely described that we couldn't use them for statistical analysis at all.

Table 1 Publications selected for the statistical evaluation of reports on abnormal animal behavior.

\begin{tabular}{ll}
\hline Berberich et al. (2013) & Li et al. (2009) \\
Boscowitz (1890) & Lindberg et al. (1981) \\
Chen et al. (2000, 2010) & Lomnitz (1994) \\
de Liso et al. (2014a, 2014b) & Mallet (1862) \\
Deshcherevskii and Sidorin (2004) & Mott (2005) \\
Deshpande (1986) & Nikonov (1992) \\
Feng and Jiang (1992) & Nikonov (1996) \\
Fidani (2013) & Omori (1923) \\
Fidani et al. (2014) & Rikitake (1978) \\
Fritz-Roy (1839) & Rikitake and Kayano (1993) \\
Garstang (2009) & Sidorin (2003) \\
Grant and Conlan (2013) & Straser (2013) \\
Grant and Halliday (2010) & Tomoda (1998) \\
Grant et al. (2015) & Tributsch (1978) \\
Hayakawa et al. (2016a, 2016b) & Whitehead and Ulusoy (2013) \\
Hentig (1923) & Wikramanayake et al. (2006) \\
Ikeya et al. (1997) & Wood (1911) \\
Kant (1756) & Yamauchi et al. (2014) \\
Kelman et al. (2008) & Yokoi et al. (2003) \\
Lawson and Reid (1910) & Yosef (2010) \\
Li et al. (2003) & \\
\hline
\end{tabular}

Table 2 Average characteristics of 729 individual reports on abnormal animal behavior prior to earthquakes.

\begin{tabular}{lllllll}
\hline & Magnitude & Depth $(\mathrm{km})$ & $\begin{array}{l}\text { Distance } \\
(\mathrm{km})\end{array}$ & $\begin{array}{l}\text { Dobrovolsky } \\
\text { (strain) }\end{array}$ & $\begin{array}{l}\text { Precursor time } \\
\text { (days) }\end{array}$ & $\begin{array}{l}\text { Travel } \\
\text { time } \\
(\mathrm{min})\end{array}$ \\
\hline mean & 5.7 & 27 & 93 & $3.0 \mathrm{E}-02$ & 6.3 & 0.8 \\
median & 6.3 & 11 & 40 & $1.7 \mathrm{E}-04$ & 0.5 & 0.3 \\
stddev & 2.2 & 84 & 142 & $5.0 \mathrm{E}-01$ & 20.7 & 1.2 \\
$\min$ & 1.9 & 1 & 1 & $1.0 \mathrm{E}-16$ & 0.0 & 0.0 \\
$\max$ & 9.2 & 590 & 1000 & $1.1 \mathrm{E}+01$ & 270.0 & 8.3 \\
$\#$ & 140 & 50 & 492 & 489 & 596 & 495
\end{tabular}

\# is the number of reports / cases. Travel time is a proxi for the time of surface waves to propagate from the epicenter to the site of observation $(\mathrm{v} \approx 2 \mathrm{~km} / \mathrm{s})$. Note that often distance, magnitude or precursor time are not reported completely. 


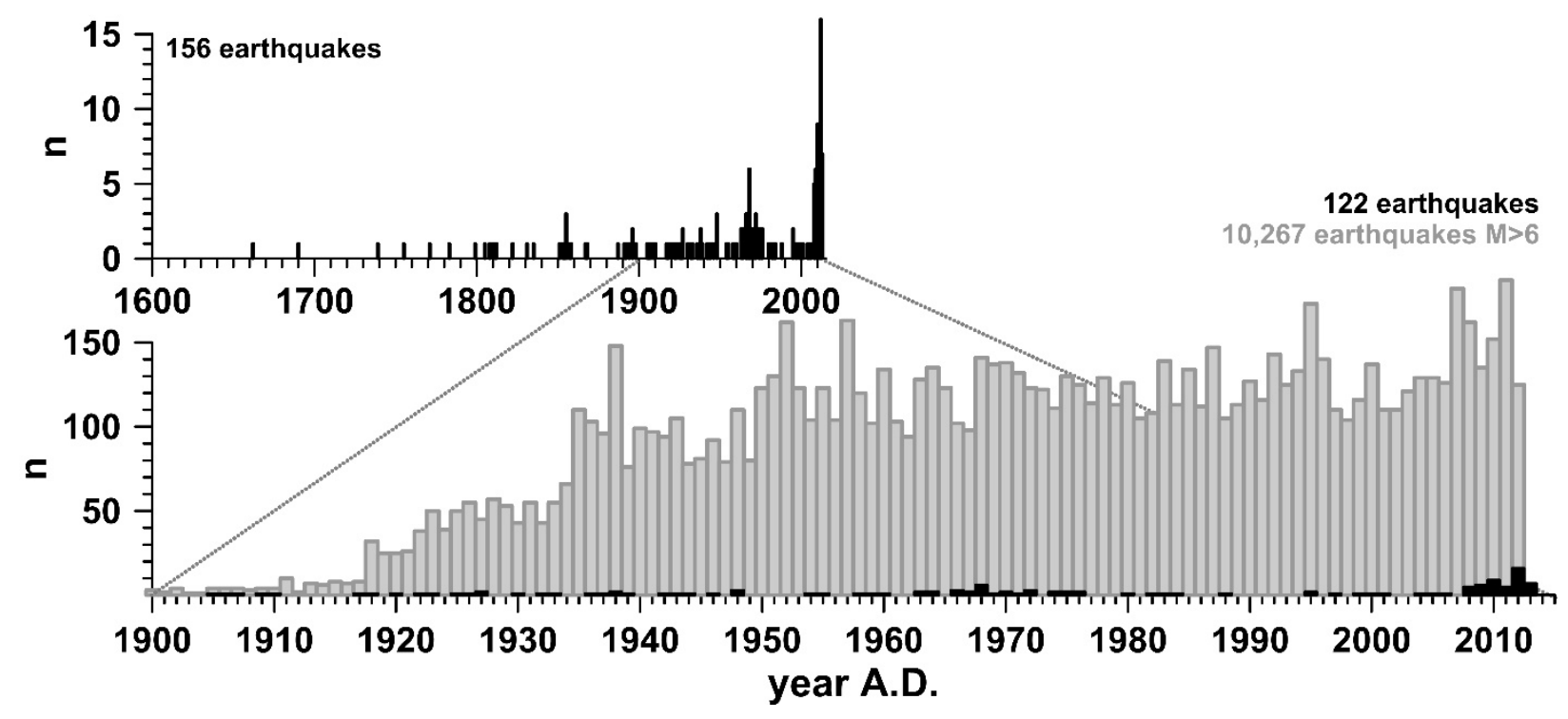

Figure 1. Earthquakes for which abnormal animal behavior had been reported since 1600 A.D.. Shown are the number of earthquakes per year. The lower subplot shows the number of earthquakes $M>6$ (light grey) during the last century according to GEM-ISC catalogue (InternationalSeismologicalCentre 2014) as well as 122 earthquakes (black) for which precursory animal behaviour have been claimed. Note that the apparently lower number of M>6 earthquakes before 1950 is related to catalog incompleteness.

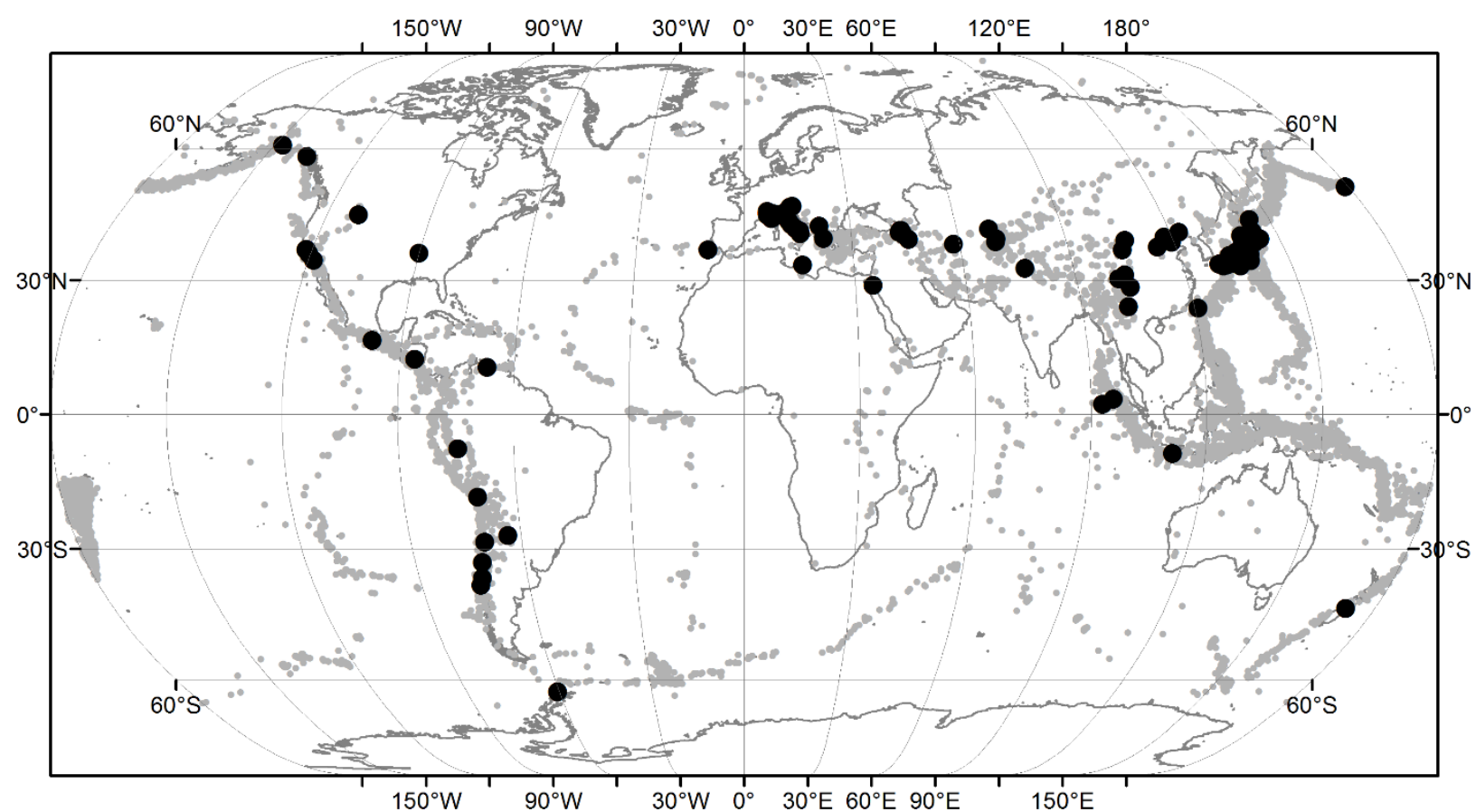

Figure 2. Earthquakes with reported animal precursors (black dots). Grey dots depict 10,267 earthquakes with M>6 between 1900 and 2012 according to GEM-ISC catalogue (InternationalSeismologicalCentre 2014). 
Our database contains the description of the animal behavior, the type of animals, and - if provided - the precursor time, the distance to the events and the event magnitude. If available, the length of the time series and the number of anomalies were entered. A summary statistics is given in Table 2.

- The numbers of reports have increased as a function of time following the ease of communication. The oldest available report is about an earthquake which occurred 1058 A.D. in Naples, Italy. 33 events occurred between 1600 and 1900, 122 events since 1900 (Fig. 1).

- Animal precursors were reported globally as illustrated in Fig. 2 where the distribution of the 122 earthquakes since 1900 is shown. For the time span between 1900 and 2012 the associated events comprise less than $1 \%$ of all earthquakes during that period with magnitudes $\mathrm{M} \geq 6$ (on average about 130 events per year).

- Abnormal animal behavior as a precursor to earthquakes was reported from more than 25 countries of all continents, but most of the reports are from New Zealand, Japan, Italy, and Taiwan. The dataset is dominated by just 3 earthquakes (Table 3): 217 cases were reported related to the 2010 Darfield Mw 7.1earthquake in New Zealand. About 77 cases refer to the 1984 Naganoken Seibu M 6.8 earthquake in Japan, and 62 reports are related to the 2009 L'Aquila $M_{\mathrm{w}} 6.3$ event in Italy. 356 reports are related to these 3 events alone, making up about $50 \%$ of the total evaluated reports.

- Although earthquakes are evenly distributed among the months of the year, the animal precursor observations show a slightly increased number for earthquakes occurring in February, April and May (Fig. 3a).

- Many animal precursors are reported within one day before the main shock, with a clear maximum in the hour before the event (Fig. 3b). Within the hour preceding the earthquake, almost $60 \%$ of the cases fall within the last 5 minutes.

- Earthquake magnitudes in our database of animal earthquakes precursors range between 2.0 and 9.2 (referring to the 1964 Great Alaska Earthquake). Nevertheless, the majority of reports relates to earthquakes with magnitudes above M 6 (Fig. 4a).

- Most precursors were observed within $100 \mathrm{~km}$ of the epicenter (Fig. 4b), about $70 \%$ within $50 \mathrm{~km}$.

For the 729 published reports on abnormal animal behavior, only 16 time series are presented in graphical form (one time series contains no anomaly, another one refers to a sequence of pre-, co-, and postseismic activities). The median length of these 14 time series is 9.4 weeks, the longest one is slightly more than one year. 
(a)

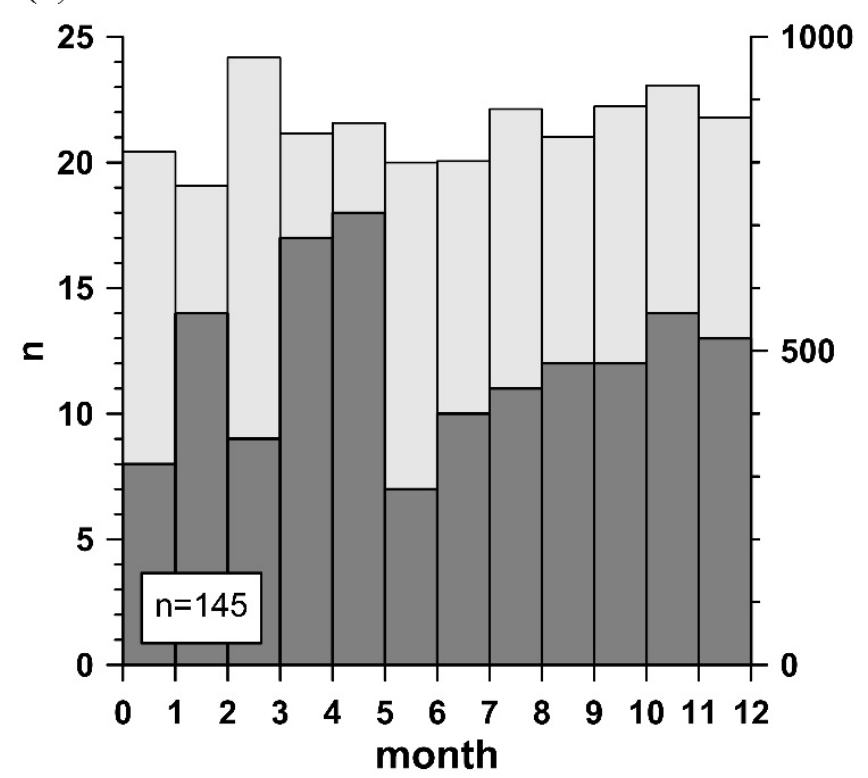

(b)

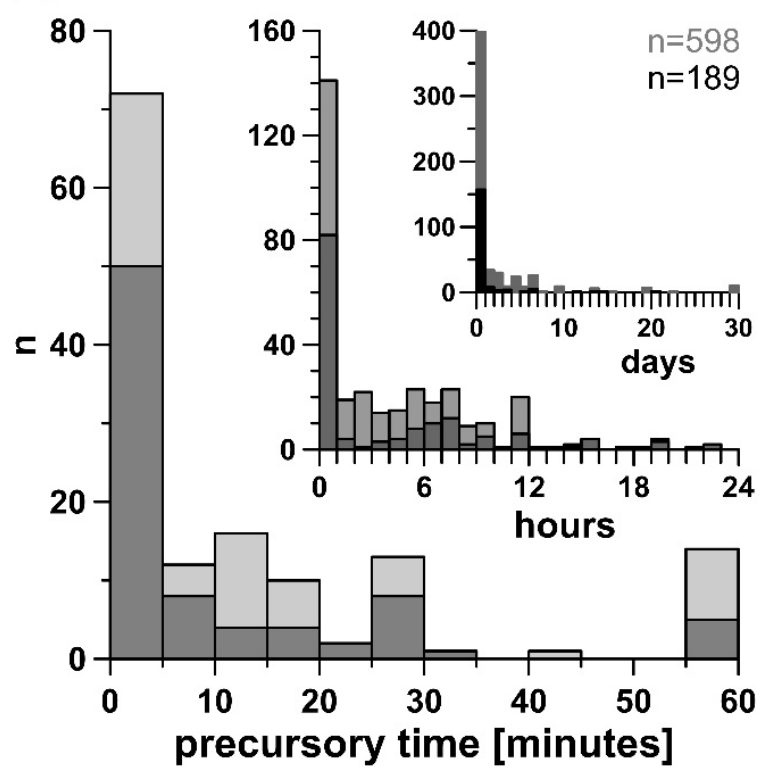

Figure 3. (a) Number of animal precursors per month of the year (dark grey, left Y-axis). Columns in light gray (right Y-axis) represent the distribution of 10,267 earthquakes $M \geq 6$ between 1900 and 2012 according to InternationalSeismologicalCentre (2014). (b) Animal precursory times shown for 30 days, 24 hours, and 60 minutes before the earthquake. Within each histogram of (b) the darker shading refers to the 2010 Darfield Mw 7.1 earthquake in New Zealand.

(a)

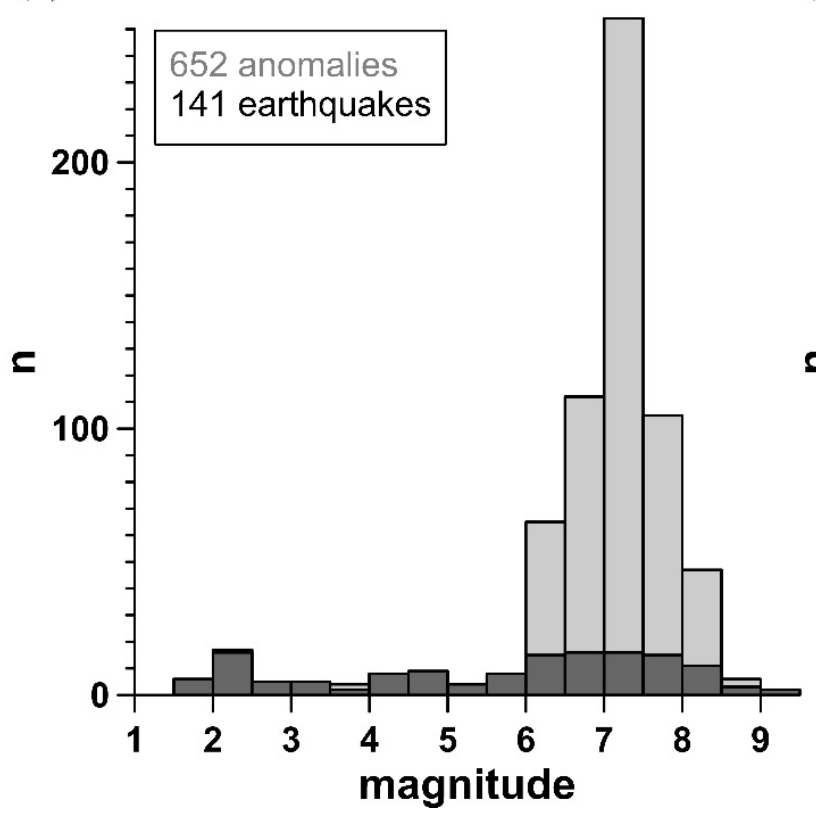

(b)

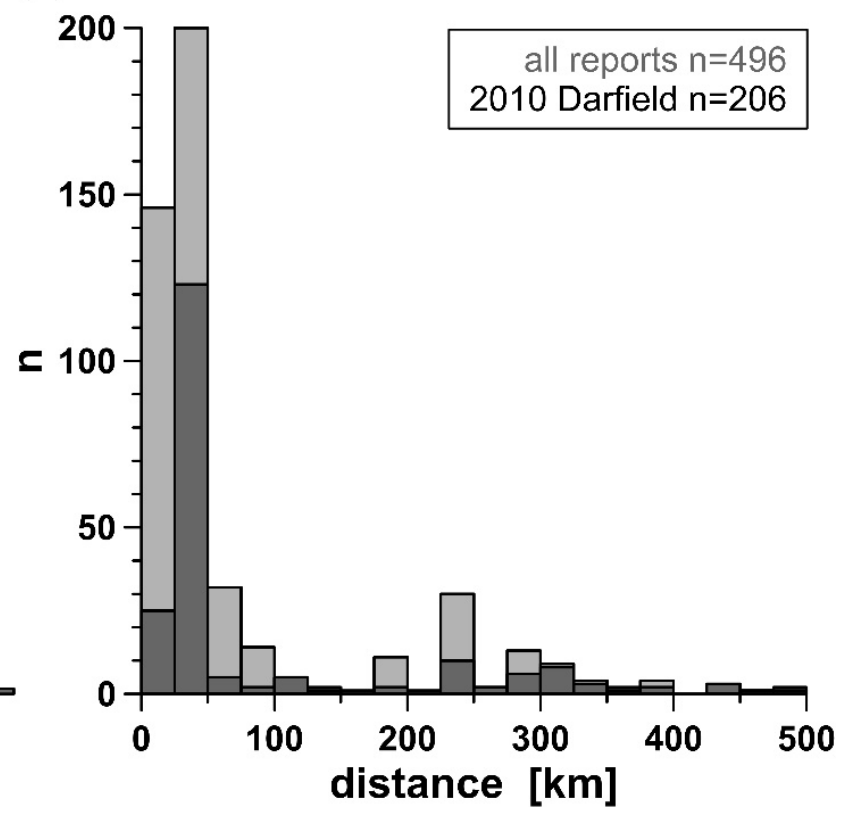

Figure 4. (a) Distribution of reports as a function of magnitude. The light grey histogram shows the number of reported animal precursors, whereas dark grey refers to the number of related earthquakes. (b) Number of animal precursors as a function of distance to the epicenter. Legend: light gray - all reports, dark gray - reports related to 2010 Darfield M 7.1 earthquake in New Zealand. 
Table 3 Earthquakes with the most reports about abnormal animal behavior.

\begin{tabular}{lcccccccccc}
\hline Year & Earthquake & Country & Mag & Dist & pt (days) & $\#$ & Mam & Bird & Fish & Rept \\
\hline 2010 & Darfield & New Zealand & 7.1 & 114 & 3.7 & 217 & 172 & 38 & 2 & 5 \\
1984 & Naganoken Seibu & Japan & 6.8 & 23 & 6.4 & 77 & 21 & 25 & 15 & 14 \\
2009 & L'Aquila & Italy & 6.3 & 44 & 17.5 & 62 & 24 & 18 & 6 & 14 \\
1923 & Kanto & Japan & 7.9 & 49 & 12.7 & 33 & 2 & 0 & 30 & 1 \\
1933 & Sanriku & Japan & 8.3 & 279 & 7.3 & 28 & 11 & 4 & 13 & 0 \\
1999 & Chi-Chi & Taiwan & 7.7 & 23 & 7.1 & 24 & 7 & 3 & 3 & 11 \\
\hline
\end{tabular}

Legend: Mag, Dis - magnitude and distance of the earthquake, \# - number of reports, pt - average precursory time, Mam - Mammals, Rept - Reptiles.

\section{Discussion}

In our study we do not discuss the sense of animals for physical or environmental parameter fluctuations, or the plausibility of such assumptions, but concentrate only on a statistical analysis in comparison to other precursory studies and the knowledge of earthquake mechanisms.

\subsection{Magnitude-Distance relations}

As discussed in section Earthquake process, our seismologic and geodetic observations as well as our current process understanding indicate that the nucleation process accelerates with time, but the nucleation size of precursory slip in the rupture zone is limited in its spatial extend and its magnitude. Furthermore, the associated elastic deformations are known to quickly decay with distance and other sources of strain variations such as tidal changes are dominating at larger distances. The possible slow-slip nucleation phase of an earthquake may lead to secondary effects at the Earth surface, which may be felt by animals. For instance, precursory changes of groundwater chemistry before two earthquakes in Iceland were suggested to be caused by crustal dilatation during stress built-up before the events (Skelton et al., 2014). Solid Earth tides induce strains of the order of $\varepsilon_{\text {tidal }}=10^{-8}$. Thus, a strain of $10^{-8}$ poses a limit for distinguishing between an earthquake preparatory strain and the daily strain loading by Earth tides. Precursors related to changes of elastic strain should be detectable, if at all, only in short distances and close in time.

Figure 3 shows that most anomalies of animals are detected directly before the mainshock with an overall accelerated detection rate with time approaching the mainshock time. Within the hour preceding the earthquake, almost $60 \%$ of the cases fall within the last 5 minutes. Other studies indicated slightly different precursor times for abnormal animal behavior. For instance, Tributsch (1978) studied 78 earthquakes and found an average precursor time of 21 hours with only small deviations from continent to continent. Rikitake (1994) obtained an average precursor time of 10 hours for earthquakes in Japan. In mainland China 81\% of anomalies occurred within 10 days before the earthquakes (Lu et al., 2015).

About $70 \%$ of the observational claims were observed within $50 \mathrm{~km}$ distance of the epicenter (Fig. 4b). Since we restricted our dataset to published papers, the reported cases might be skewed by authors, reviewers, and editors towards observations close to the earthquake, both in space and time. We cannot know how much the statistics is influenced by pre-conceived ideas. Nevertheless, the median distance for animal precursors is $40 \mathrm{~km}$ compared to $100 \mathrm{~km}$ for gas 
emission anomalies (Cicerone et al., 2009). A retrospective analysis of precursors to the $1999 \mathrm{M}$ 7.6 Izmit earthquake revealed similar results (Whitehead et al., 2004). Influence distance ranges for the 2010 M 7.1 Darfield earthquake were suggested at $56 \mathrm{~km}$ for $73 \%$ of all reports (Whitehead and Ulusoy, 2013). One third (34\%) of abnormal animal behavior in mainland China between 1966 and 2002 was reported from the epicentral area, another 38\% from sites within $100 \mathrm{~km}$ from the epicenter (Lu et al., 2015).

The magnitude-distance range of reported precursory anomalies can be discussed from theoretical models on the maximal expected strain in the rock. Using the tidal strain of $\varepsilon_{\min }=10^{-8}$ as limit, Dobrovolsky et al. (1979) estimated the maximal distance at which a precursory anomaly can be still causally related to the physical earthquake preparation process. They assumed that the rock volume is altered by cracking in a circular rock volume around the epicenter of the future main shock, and thus generates elastic strain and tilt far from the epicenter. The maximum strain is proportional to the affected volume and attenuates with $\mathrm{r}^{-3}$, where $r$ is the hypocentral distance. Using published estimates of volume of the focal zone of earthquakes Dobrovolsky et al. (1979) estimated a maximal strain radius of $r_{\max }=\left(\varepsilon_{\min }\right)^{1 / 3} 10^{(0.5 \mathrm{M}}$ -2.73) (for $\mathrm{M}>5$ ) and $\mathrm{r}_{\max }=\left(\varepsilon_{\min }\right)^{1 / 3} 10^{(0.5 \mathrm{M}-3.06)}$ (for $\mathrm{M}<5$ ). Although these equations are widely used until today (e.g., Yamauchi et al., 2017), the research on nucleation phases has advanced since 1979. Ohnaka $(2000,2013)$ derived a scaling relation between the seismic moment $\mathrm{M}_{0}$ of the main shock and radius $\mathrm{L}_{\mathrm{c}}$ [in $\mathrm{m}$ ] of the slow slip nucleation phase of fault instabilities. From laboratory and field data they derived a scaling as $\mathrm{M}_{0} \approx 10^{9}\left(2 \mathrm{~L}_{\mathrm{c}}\right)^{3}=810^{9} \mathrm{~L}_{\mathrm{c}}{ }^{3}$, where $\mathrm{M}_{0}$ [in $\mathrm{Nm}$ ] is the seismic moment of the main-shock to come.

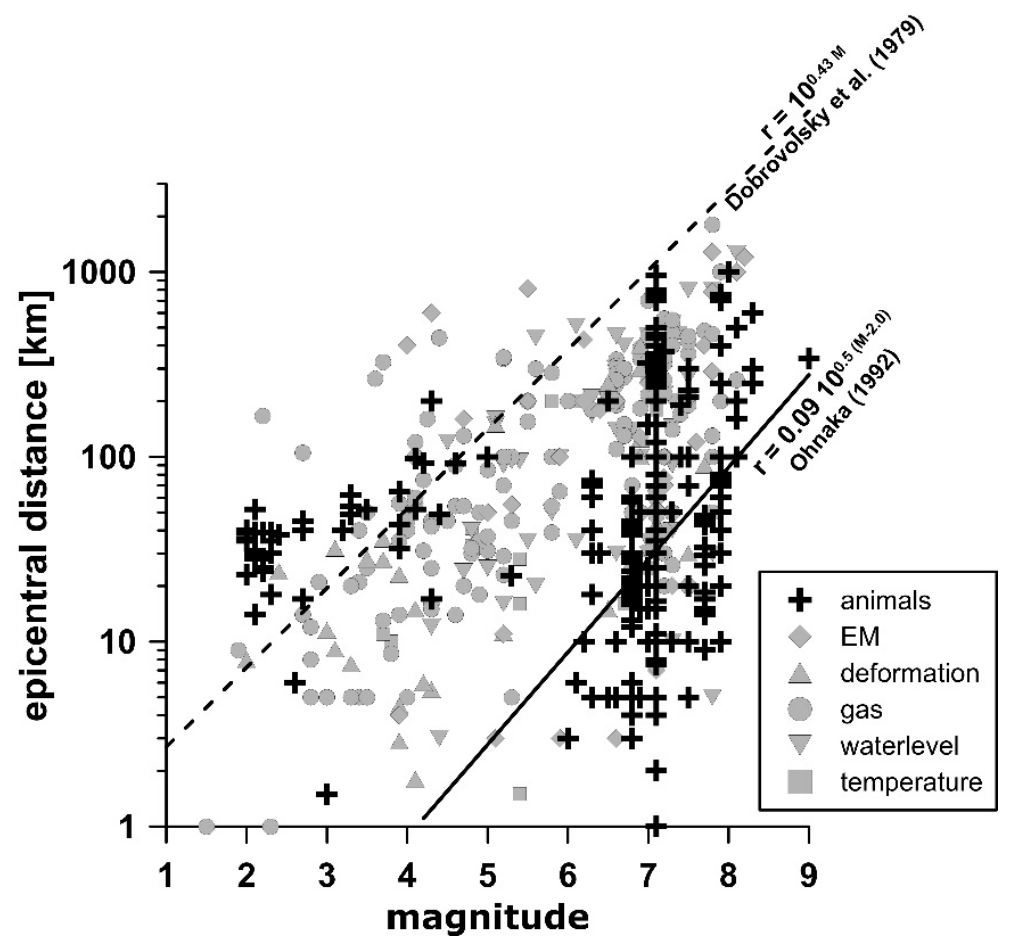

Figure 5. Distance vs. magnitude relation for proposed animal precursors (crosses). Proposed electric and magnetic field (EM), deformation, gas, water level, and temperature precursors are shown for comparison (grey symbols) from (Cicerone et al., 2009). Solid and dashed lines indicate the maximum distance at which precursors might be expected according to Ohnaka (1992) and Dobrovolsky et al. (1979), respectively. For example, an M7 earthquake would be detectable within a radius of about $30 \mathrm{~km}$ (Ohnaka) or 1,000 km (Dobrovolsky), depending on the model. 
We declare $\mathrm{M}_{0 \mathrm{Nucl}}$ as the equivalent moment of the nucleation phase, and use a standard crack model with $\mathrm{M}_{0 \mathrm{Nucl}} \approx 16 / 7 \Delta \tau \mathrm{L}_{\mathrm{c}}{ }^{3}$ to estimate the factor $\mathrm{M}_{0 \mathrm{Nuc}} / \mathrm{M}_{0}$, or alternatively the magnitude difference $\Delta \mathrm{M}_{\mathrm{w}}=\mathrm{M}_{\mathrm{w}}-\mathrm{M}_{\mathrm{wNucl}}$ considering the relation between seismic moment and moment magnitude according to $\mathrm{M}_{0}=10^{1.5 \mathrm{Mw}+9.1}\left[\mathrm{M}_{0}\right.$ in $\left.\mathrm{Nm}\right]$ (Kanamori, 1977). For stress drop values ranging between $\Delta \tau=1 \mathrm{MPa}$ and $10 \mathrm{MPa} \Delta \mathrm{M}_{\mathrm{w}}$ is in the range between $\Delta \mathrm{M}_{\mathrm{w}}=1.69$ and 2.36. For a rough estimate we set $\Delta \mathrm{M}_{\mathrm{w}} \approx 2$. Assuming as first order approximation a point source in full space, we can estimate the maximal strain from the nucleation phase by $\varepsilon_{\max }=\mathrm{M}_{0 \mathrm{Nuc}} / 2 \pi \mu 1 / \mathrm{r}^{3}$ (e.g. Aki and Richards, 2002), where $\mu$ is the shear modulus and $r$ the distance to the source. Setting $\varepsilon_{\max }$ to the limit value $10^{-8}$, we calculate the strain radius by

$$
\mathrm{r} /(1 \mathrm{~km}) \leq 1 / 11.410^{0.5(\mathrm{M}-2)}
$$

The limiting value for $r$ gives the maximal distance to which we can expect strain induced by a nucleation phase to be above the tidal strain of $10^{-8}$. The strain radius estimated from the scaling of nucleation phase asperities (equation 1) is significantly smaller than the Dobrovolsky strain.

Fig. 5 shows the distance vs. magnitude relation for proposed animal precursors. Proposed physical precursors (electric and magnetic field, deformation, gas, water level, and water temperature) compiled by Cicerone et al. (2009) are shown for comparison. The maximum distance at which precursors might occur according to Ohnaka's model is smaller than that based on Dobrovolsky's estimation. The majority of animal precursors is related to earthquakes above M6. A second cluster of animal precursors plots between M2 and M4, leaving an apparent gap between M4 and M6. Since most of the second cluster plots above the Dobrovolsky relation meaning strains below $10^{-8}$ as low as about $10^{-11}$ - a mechanical link between the prepreatory earthquake strain and the claimed abnormal animal behavior seems unlikely, if not impossible. Although the majority of animal precursors plots below Dobrovolsky's line indicating strains of the order of $10^{-8}$, only few meet the Ohnaka criterium. This indicates that in almost all cases the induced total strain at the location of the observed anomaly is only of the order of tidal stress changes occurring every 6 hours or less.

In addition to the total strain, the induced strain rates can be compared to tidal strain rates. For the same total strain, long nucleation phases of the earthquake rupture process would lead to significantly smaller strain rates compared to tides although the total strain is comparable. Vice versa, the strain rate might be significantly larger and thus potentially observable/sensible for nucleation times much shorter than 6 hours. To explore this, we have calculated the strain rates at the location and time of the observed anomalies by the ratio between the total induced strain and the precursor time. This ratio is an upper limit because the assumed nucleation process is accelerating with time and the nucleation likely started before the anomaly. The limit of the strain rate is defined by the tides, $10^{-8} / 6[1 / \mathrm{h}]$.

$$
\mathrm{r}_{\max }=0.15910^{0.5(\mathrm{M}-2.0)} \mathrm{t}_{\mathrm{p}}^{-1 / 3}
$$

with distance $r$ in $[\mathrm{km}]$ and precursor time $t_{p}$ in [hour]. For a given precursor time $t_{p}$ of an anomaly related to an earthquake of magnitude $\mathrm{M}$, the strain rate due to the nucleation process is only expected to exceed the tidal strain rates at anomaly distancies $r<r_{\text {max }}$. Figure $6 a-d$ shows the epicentral distance vs. precursor time relation for animal precursor and $r_{\max }$ according to equation 
2 for various magnitudes. In many cases, the data point of the anomaly lies above the line related to the magnitude of the corresponding earthquake, which indicates that the strain rates induced by the nucleation process should have been insignificant at the location and time of the anomaly. Figure $6 e$ indicates that only in about $35 \%$ of the anomalies, the strain rate is found to be significant based of Eq. (2).

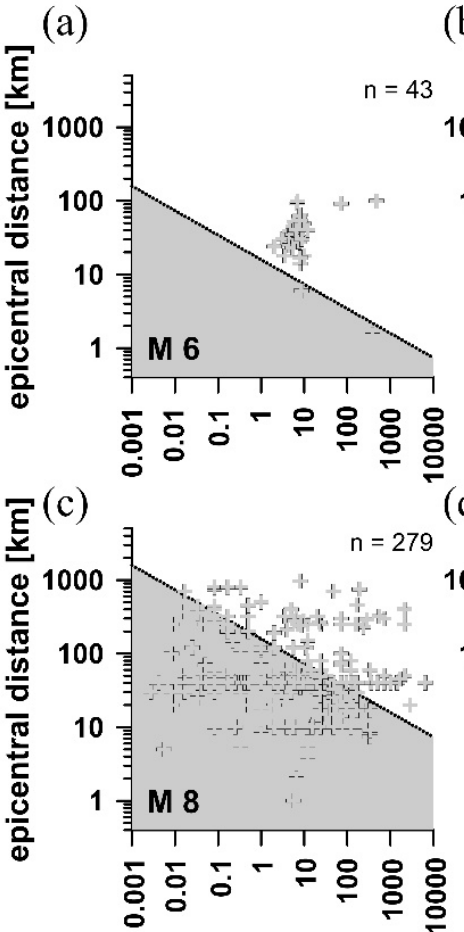

precursor time [hours] (b)

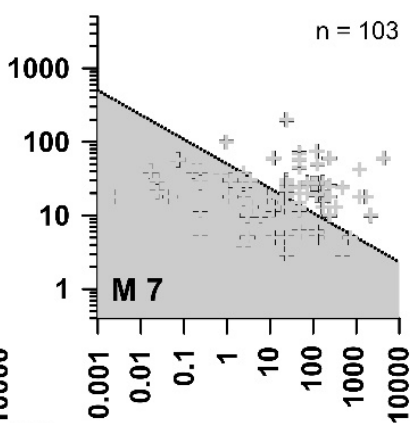

(d)

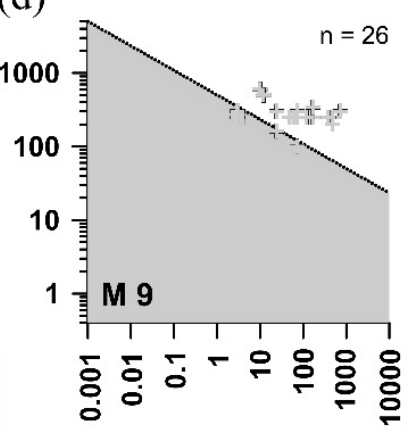

precursor time [hours] (e)

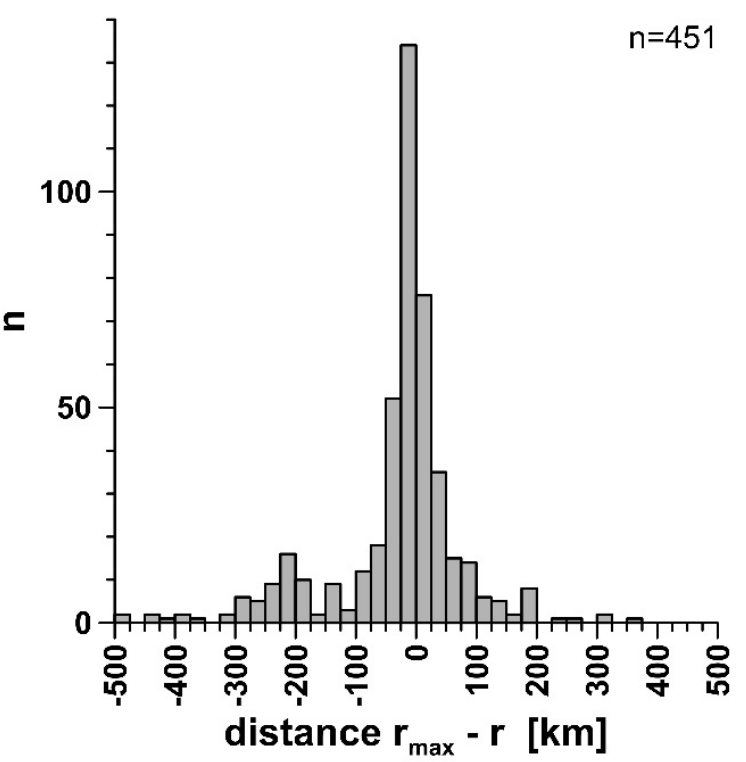

Figure 6. (a-d) epicentral distance vs. time for proposed animal precursors for different magnitudes $M$ of the related earthquake. Lines indicate the maximum distance rmax according to equation 2 at which precursors might occur. The estimated strain rate of the assumed nucleation process exceeds that of the earth tides only at anomaly locations which are below the corresponding lines related to $M$ (shaded areas in subplots $a-d$ ). (e) distribution of the difference rmax $-r$ (observed). In about $35 \%$ of the cases the difference is positive, meaning that preparation strains - if they exist - are potentially large enough to generate precursory anomalies.

\subsection{Foreshocks}

Some of the detected animal precursors may be explained by elastic waves from foreshocks, which animals may have felt. In this case, the animal behavior would be only a secondary effect and would not have additional predictive power. Foreshocks occur before approximately $10 \%$ of main shocks (Reasenberg, 1999). An example is the $2009 \mathrm{M}_{\mathrm{w}} 6.3 \mathrm{~L}$ 'Aquila, Italy earthquake which was preceded by a sequence of foreshocks over several months. Unfortunately, foreshocks have not systematically been reported and analyzed in the corresponding animal-related publications so that a one-by-one evaluation seems not possible. However, a statistical approach may help. The GEM-ISC catalog (InternationalSeismologicalCentre, 2014) from 2000-2012 has a magnitude of completeness of $\mathrm{M}_{\mathrm{c}}=5$.6. We assume that such a foreshock may be felt by animals at a distance of 100 kilometers, which would have an intensity of V-VI (e.g. Faenza and Michelini, 2010). Smaller events might be also felt, but our analysis is only limited to earthquakes above the completeness threshold of the global catalog. We search all foreshocks in 
epicentral distances up to 100 kilometers and within 60 days before mainshocks of $M_{w} \geq 6$. We find that $16 \%$ of the mainshocks were preceded by such foreshocks within 60 days; whereas only $7 \%$ (3\%) of the mainshocks were preceded by foreshocks within 1 day (1 hour). Figure 7 shows that these foreshocks are strongly clustered in space and time relative to the mainshock. The temporal clustering is similar to the observed one for animal precursors. In Figure 8 we compare the distribution of foreshock times with that of animal anomalies before the mainshocks. The shape of both distributions is strikingly similar, suggesting that at least part of the reported animal precursors are in fact related to foreshocks.

(a)

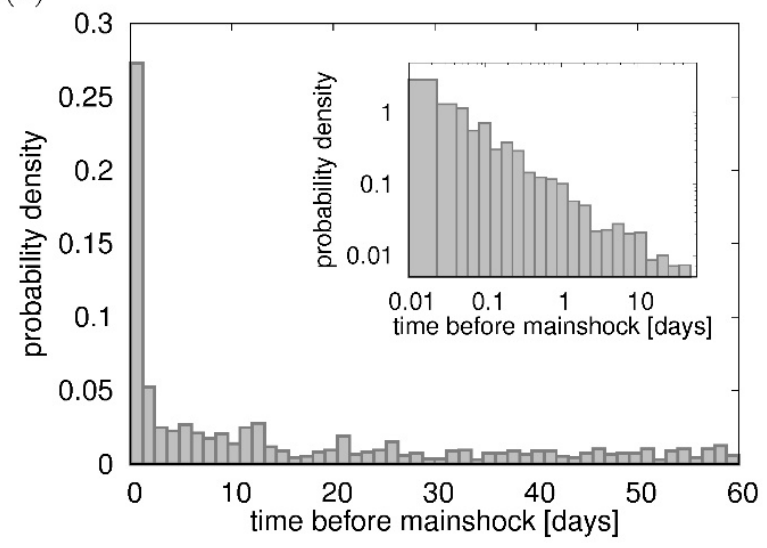

(b)

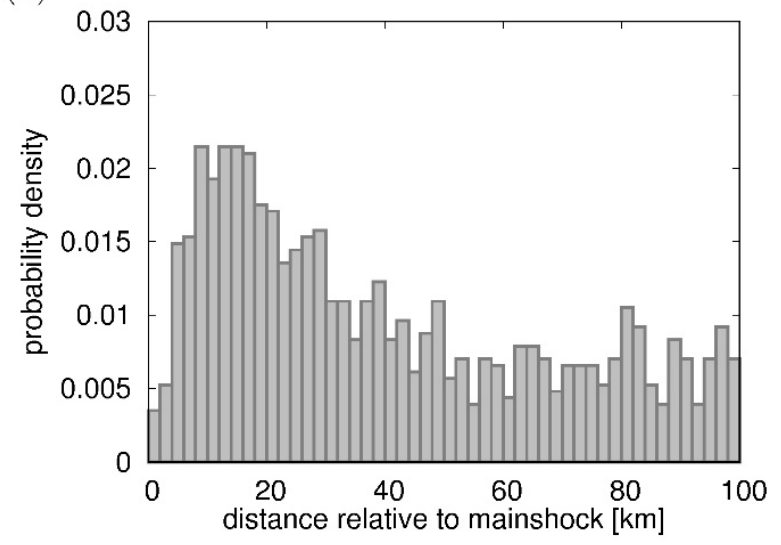

Figure 7. Probability density distribution of earthquakes preceding mainshocks of Mw>6 in the ISC-GEM catalog: (a) occurrence times relative to the mainshock (b) distance to the mainshock epicenter.

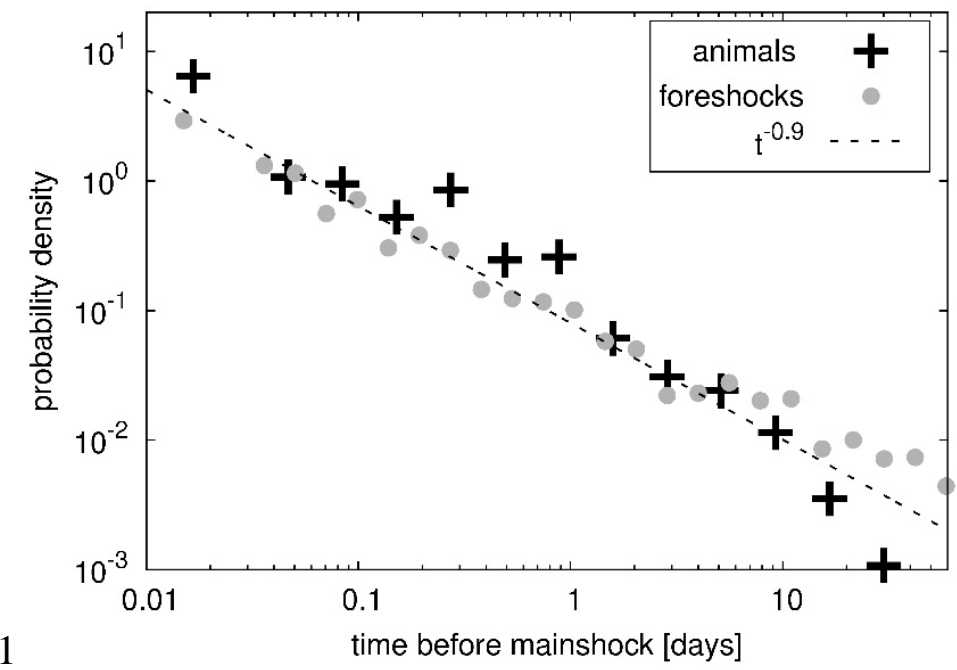

Figure 8. Probability density (number of events normalized by the bin width and total number) of earthquakes preceding mainshocks of $M w>6$ in the ISC-GEM catalog compared to the occurrence of animal precursosrs before the mainshock. The dashed line indicates the function $0.08 * t-0.9$. The similar slope of both distributions suggests that at least part of the reported animal precursors are in fact related to foreshocks.

About $60 \%$ of the reported precursory times were 5 minutes or less before the earthquake (Fig. 3b). In case of merely anecdotal reports, it can be assumed that the mentioned precursor time is not reported with respect to the origin time, but with respect to the point in time when the 
reporter felt the earthquake. This is supposed to be the arrival of the first stronger phase, like the P-wave, S-wave, or surface wave. It may therefore be questioned whether a part of the abnormal animal behavior is related to the arrival of the first strong wave from fore- and main shocks. For instance, the traveltime of surface waves to the observation point in a distance of $100 \mathrm{~km}$ is 0.8 minutes, and therefore much smaller than the average reported precursory times. From a careful analysis of our database we find only very few cases where the P-wave arrival of the main-shock is a candidate to explain abnormal animal behavior. Examples include the response of pheasants to 23 earthquakes in Japan between 1913 and 1916 with a precursor time of only 8 seconds or less (mean value of 3.6 seconds, see Omori, 1923). This is in the range of the expected uncertainty of the estimated origin time, and animals may have felt the first arriving waves. Few similar cases may explain observations during the $2010 \mathrm{M}_{\mathrm{w}}$ 7.1 Darfield, New Zealand earthquake (Whitehead and Ulusoy, 2013).

\subsection{Length of timeseries}

We reviewed about 180 publications on precursory claims, including more than 700 records of abnormal animal behavior, where only 16 of these presented time series at all. 14 timeseries showed pre-seismic anomalies of animal behavior. Most of the time series are much shorter than 1 year (Fig. 9a), the median being about 14 weeks. In comparison to earthquake precursor studies from radon anomalies, groundwater chemistry, temperature and water level fluctuations, the presented time series for animal behavior are all short. This, and the examples given, show the limitations which makes a statistical analysis and discussion difficult. Environmental parameters are rarely monitored or documented. The question of completeness of the assessment is only rarely raised, but is important for the interpretation.

For instance, the occurrence of an earthquake with $\mathrm{M}>\mathrm{M}_{\mathrm{c}}$ may be considered a binary event, which either occurred or did not occur at a given time and location. $\mathrm{M}_{\mathrm{c}}$ is the magnitude of completeness of a seismological catalog, meaning that the earthquake data can be assumed to be complete. The abnormal behavior may either be given as binary event or, in few cases, as time dependent patterns if a monitoring program was realized. It is important that the anomaly is carefully identified and verified against the background. In our database of abnormal animal behavior, completeness has rarely been discussed, unfortunately.

The problem can be illustrated for the example of the birth of a baby as a "signal". In order to analyze whether the rate of births in a given region and time before the earthquake is anomalous, a complete assessment in the region and a sufficiently long time before the event is needed. The completeness of the pre-event time series is a necessary requirement for validation. We assume a hospital where about 4 babies are born on average every day, with some more during working days and few during weekend. If the earthquake occurs on Monday morning, the rate of babies would have decreased just before the earthquake. A correlation analysis with a time series of 2 days before the earthquake would indicate a positive result. It is obvious that the validation of a causal relationships via correlation may have pitfalls and must be done carefully.

Firstly, a positive correlation for more than one earthquake needs to be demonstrated (e.g. occurring not only on Mondays). Secondly, the temporal-spatial pattern of the anomalies needs to be assessed and considered. The longer the time series are, the better. If toads have a mating season during 2 weeks in April, the correlation of activity with an earthquake in April may not mean much. Animals react strongly on seasonal changes and weather conditions. Therefore, a 
recording period of at least one year may be recommended. Figure 9 showed that the majority of reports presented shorter time series, which is worrisome.

(a)

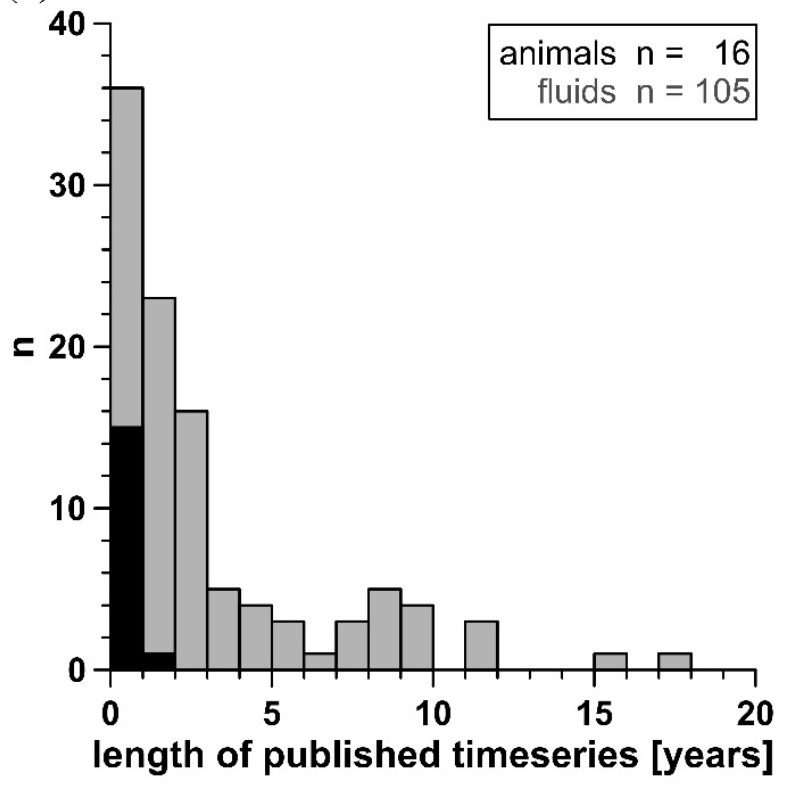

(b)

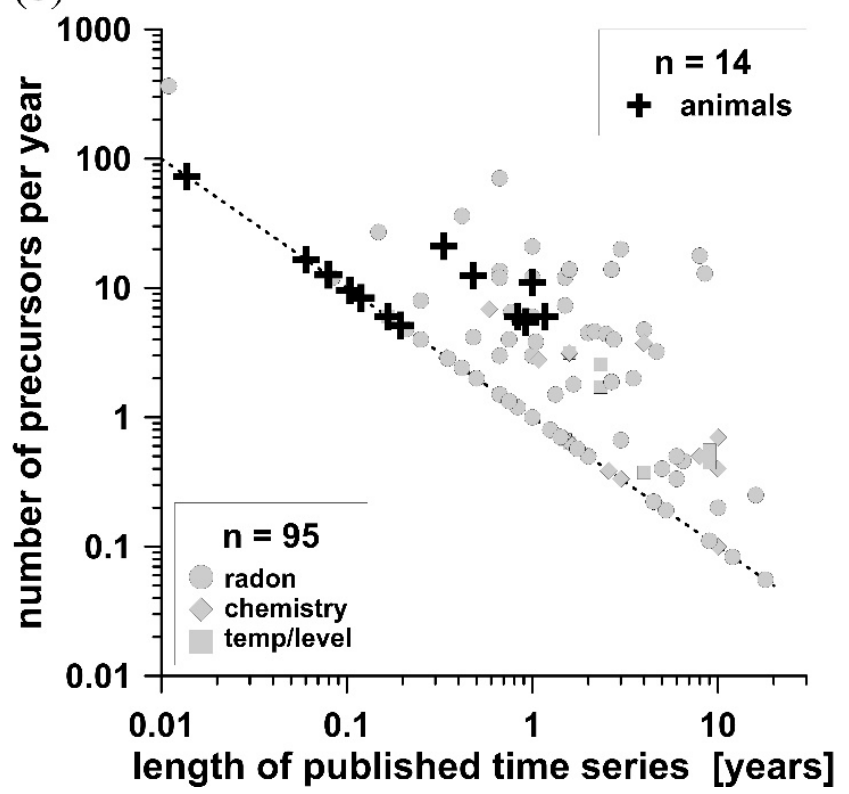

Figure 9. (a) Frequency distribution of the lengths of the published timeseries for animals and fluid-related precursors. (b) Animal precursor rate (number of precursors per length of time series extrapolated to number of precursors per year - black crosses) vs. length of the published time series. Grey symbols depict fluid-related precursors (radon, groundwater chemistry, water temperature, water level) adapted from Woith (2015) for comparison. The dashed line indicates a 1/time relation, referring to the case of one detected anomaly in the analyzed time period.

The length of the observation time is also related to the investigated precursory time. If toads breed once a year, a precursory time for increased activity of up to 6 month would give a positive hit for $50 \%$ of random earthquakes. The length of the anomaly occupies up to $23 \%$ of the complete timeseries (11 \% on average). Thus, the statistics of claimed animal precursors is anything but robust. In some cases, the presented timeseries are a selection from a longer period of observations. The criteria for the selection are not specified, generally. This leads to the effect, that the number of reported precursors and the length of the presented timeseries are apparently negatively correlated (Fig. 9b). The lack of long-term records had also been identified for classical physical earthquake precursors as critical to assess the signal and noise characteristics of a monitoring parameter (Woith, 2015; Wyss, 1991, 1997), but for the animal dataset the issue is even more pronounced.

In statistical analysis and the field of machine learning, a confusion or error matrix analysis is recommended for statistical classification, which considers the true and false positives and negatives from a complete assessment of the binary events. Finally, we mention another possible pitfall of time series analyzed by multi-regression and correlation. Seismicity and precursory anomalies are often presented as positive functions with large mean and low standard deviations. In such a case, high normalized cross correlation values can be obtained, even if the two functions to be tested are purely random (Oprsal and Eisner, 2014). 


\section{Summary}

The study of abnormal animal behavior is experimentally difficult, if compared with the approach to install instruments and sensors to measure variations of physical field parameters. However, our review indicates that experiments are not the only problem, since data collection, processing, and interpretation is often poor. For many of the reviewed case studies severe elementary problems are obvious which make a scientific evaluation and validation difficult if not impossible. This is related to the data assessment approach and the definition of anomalies, the incompleteness of ensembles, and the processing and interpretation of data.

Whereas most publications on that subject claim to have observed precursory abnormal animal behavior, few authors try to substantiate their claims and discuss physical mechanisms behind the animal behavior (see Supplementary Material). Formulating a hypothesis and then testing the null hypothesis by falsification according the theory of Karl Popper (1935) should be mandatory in science. A sound testing requires carefully designed observations lasting for years under controlled environmental conditions. By reviewing about 180 publications on precursory claims of abnormal animal behavior, typical weaknesses of a majority of cases include

- the reported time series are mostly too short and no baseline of "normal" behavior is defined; often only a selected part of the complete timeseries is presented. The assessment of signal and noise characteristics is thus often not possible.

- the definition of the anomaly is often not quantitative or strict and sometime even unclear. Additionally, the precursory periods and time lags appear to be often arbitrary.

- the question of completeness of the assessment has only rarely been discussed, including the comparative study of possible true negative or false negative or positive cases.

- the environmental parameters are rarely monitored or documented, as e.g. temperature and weather conditions, rainfall, thunder storms.

- Most of the reports about unusual animal behavior are made retrospectively, i.e. the strange animal beghavior is only recognized after the earthquake.

- the state and health condition of the animals or animal populations are rarely documented, the same holds for external stress or danger/predators.

Note, that only the last two items are animal-specific. All other items are equally critical in most classical physical precursor studies. It is clear that because of such weaknesses the assessment and validation of claims of abnormal animal behavior is difficult.

\section{Yes/No Questions}

For evaluating the quality of reports on animal precursors, we propose a scheme of yes and no questions, which should be considered in any planning, evaluation, and publication of animal related anomalous behavior:

1. Is the experimental setup and monitoring procedure clearly described and reproducible?

2. Are anomalies comprehensively described and are the pattern and threshold values quantified?

3. Is the assignment between the anomaly and the earthquake based on clearly defined rules (magnitude-distance relations)?

4. Is the full data set presented in graphical form?

5. How often do anomalies occur but are not followed by an earthquake?

6. Have observations started and been documented before the earthquake? 
7. Is quantitative information given on seismicity, including background seismicity, on foreshocks, seismic network performance, catalogue completeness, source parameters and their uncertainties, and on the distance to measurements?

8. Have environmental parameters been measured and documented?

9. Are the same precursory anomalies documented for more than one earthquake?

10. Are the time series much longer than the anomaly?

11. Is a statistical hypothesis testing approach considered (e.g. false positive and negatives)?

12. Is a (physical) mechanism presented to explain the abnormal (animal) behavior?

13. Is the state and health condition of the animals or animal populations documented?

14. Is information on predators given?

15. Is it proven that the animal behavior is really unusual?

Note, that only the last 3 questions relate specifically to animals.

\section{Acknowledgements}

We thank Rui Yan from China Earthquake Networks Center, Beijing, for discussions and references about animal earthquake precursor studies in China. The manuscript greatly benefitted from critical comments and constructive proposals by Max Wyss and two anonymous reviewers.

\section{References}

Aggarwal, Y. P., L. R. Sykes, J. Armbruster, and M. L. Sbar (1973). Premonitory changes in seismic velocities and prediction of earthquakes, Nature 241 101-104, doi: 10.1038/241101a0.

Aki, K., and P. G. Richards (2002). Quantitative Seismology, University Science Books, 700.

Apostol, A., T. Moldoveanu, A. Sarlea, and T. Victorin (2016). Can Red Wood Ants Predict Earthquakes?, J. Earth Sci. 2 1-10.

Bakun, W. H., B. Aagaard, B. Dost, W. L. Ellsworth, J. L. Hardebeck, R. A. Harris, C. Ji, M. J. S. Johnston, J. Langbein, J. J. Lienkaemper, A. J. Michael, J. R. Murray, R. M. Nadeau, P. A. Reasenberg, M. S. Reichle, E. A. Roeloffs, A. Shakal, R. W. Simpson, and F. Waldhauser (2005). Implications for prediction and hazard assessment from the 2004 Parkfield earthquake, Nature 437 969-974, doi: 10.1038/Nature04067.

Bakun, W. H., and A. G. Lindh (1985). The Parkfield, California, earthquake prediction experiment, Science 229 619-624, doi: 10.1126/science.229.4714.619.

Berberich, G., M. Berberich, A. Grumpe, C. Wohler, and U. Schreiber (2013). Early results of three-year monitoring of Red Wood Ants' behavioral changes and their possible correlation with earthquake events, Animals 3 63-84, doi: 10.3390/ani3010063.

Berberich, G., and U. Schreiber (2013). GeoBioScience: Red Wood Ants as Bioindicators for Active Tectonic Fault Systems in the West Eifel (Germany), Animals 3 63-84, doi: 10.3390/ani3020475.

Boscowitz (1890). Earthquakes, George Routledge and Sons, London, 395.

Bouchon, M., V. Durand, D. Marsan, H. Karabulut, and J. Schmittbuhl (2013). The long precursory phase of most large interplate earthquakes, Nat. Geosci. 6 299-302, doi: 10.1038/ngeo1770.

Bouchon, M., H. Karabulut, M. Aktar, S. Ozalaybey, J. Schmittbuhl, and M. P. Bouin (2011). Extended Nucleation of the 1999 M(w) 7.6 Izmit Earthquake, Science 331 877-880, doi: 10.1126/science.1197341.

Buskirk, R. E., C. Frohlich, and G. V. Latham (1981). Unusual animal behavior before earthquakes; a review of possible sensory mechanisms, Rev. Geophys. Space Phys. 19 247-270, doi: 10.1029/RG019i002p00247.

Chen, A. T., T. Ouchi, A. M. Lin, J. C. Chen, and T. Maruyama (2000). Phenomena associated with the 1999 ChiChi earthquake in Taiwan, possible precursors and after effects, Terr. Atmos. Ocean Sci. 11 689-700.

Chen, L. L., X. Hu, J. Zheng, H. H. Zhang, W. Kong, W. H. Yang, T. S. Zeng, J. Y. Zhang, and L. Yue (2010). Increases in energy intake, insulin resistance and stress in rats before Wenchuan earthquake far from the epicenter, Exp. Biol. Med. 235 1216-23, doi: 10.1258/ebm.2010.010042. 
Cicerone, R. D., J. E. Ebel, and J. Britton (2009). A systematic compilation of earthquake precursors, Tectonophysics 476 371-396, doi: 10.1016/j.tecto.2009.06.008.

Crampin, S., and G. Yuan (2014). Two species of microcracks, Appl. Geophys. 11 1-8, doi: 10.1007/s11770-0140415-7.

Das, S., and C. H. Scholz (1983). Why large earthquakes do not nucleate at shallow depths, Nature 305 621-623, doi: 10.1038/305621a0.

de Liso, G., C. Fidani, and A. Viotto (2014a). Multi-parametric monitoring system of associated seismic phenomenology and unusual animal behaviour in Western Piedmont, Adv. Res. 2 303-319.

de Liso, G., C. Fidani, and A. Viotto (2014b). Unusual animal behaviour before earthquakes and multiple parameter monitoring in Western Piedmont, Earth Sci. 3 14-25, doi: 10.11648/j.earth.20140301.13.

Deshcherevskii, A. V., and A. Y. Sidorin (2004). Changes in the behavior of fishes and insects before earthquakes at the Garm test site, Dokl. Earth Sci. 399 1172-1176.

Deshpande, B. G. (1986). Earthquakes, animals and man capter III - animal repsonse to earthquakes, Proc. Indian Natl. Sci. Acad. B Biol. Sci. B52 585-618.

Dobrovolsky, I. P., S. I. Zubkov, and V. I. Miachkin (1979). Estimation of the size of earthquake preparation zones, Pure Appl. Geophys. 117 1025-1044, doi: 10.1007/BF00876083.

Faenza, L., and A. Michelini (2010). Regression analysis of MCS intensity and ground motion parameters in Italy and its application in ShakeMap, Geophys. J. Int. 180 1138-1152, doi: 10.1111/j.1365-246X.2009.04467.x.

Feng, C., and J. Jiang (1992). Quantitative observation and study on rhythmic abnormalities of activities in animals prior to earthquakes, Acta Seism. Sin. 5 857-865, doi: 10.1007/BF02651034.

Fidani, C. (2013). Biological anomalies around the 2009 L'Aquila earthquake, Animals 3 693-721, doi: 10.3390/ani3030693.

Fidani, C., F. Freund, and R. Grant (2014). Cows Come Down from the Mountains before the (Mw = 6.1) Earthquake Colfiorito in September 1997; A Single Case Study, Animals 4 292, doi: 10.3390/ani4020292.

Fritz-Roy, R. (1839). Narrative of the Surveying Voyages of HMSs Adventure and Beagle between the years 1826 and 1836, Henry Colburn, London, 694.

Garstang, M. (2009). Precursor tsunami signals detected by elephants, Open Conservat. Biol. J. 3 1-3.

Geller, R. J. (1991). Shake-up for earthquake prediction, Nature 352 275-276, doi: 10.1038/352275a0.

Geller, R. J. (1997). Earthquake prediction: a critical review, Geophys. J. Int. 131 425-450.

Geller, R. J., D. D. Jackson, Y. Y. Kagan, and F. Mulargia (1997). Earthquakes cannot be predicted, Science 275 1616-1617, doi: 10.1126/science.275.5306.1616.

Grant, R., and H. Conlan (2013). Frog swarms: Earthquake precursors or false alarms?, Animals 3 962, doi: 10.3390/ani3040962.

Grant, R. A., and T. Halliday (2010). Predicting the unpredictable; evidence of pre-seismic anticipatory behaviour in the common toad, J. Zool. 281 263-271, doi: 10.1111/j.1469-7998.2010.00700.x.

Grant, R. A., T. Halliday, W. P. Balderer, F. Leuenberger, M. Newcomer, G. Cyr, and F. T. Freund (2011). Ground Water Chemistry Changes before Major Earthquakes and Possible Effects on Animals, Int. J. Env. Res. Public Health 8 1936-1956, doi: 10.3390/ijerph8061936.

Grant, R. A., J. P. Raulin, and F. T. Freund (2015). Changes in animal activity prior to a major $(M=7)$ earthquake in the Peruvian Andes, Phys. Chem. Earth. 85-86 69-77, doi: 10.1016/j.pce.2015.02.012.

Hardebeck, J. L., K. R. Felzer, and A. J. Michael (2008). Improved tests reveal that the accelerating moment release hypothesis is statistically insignificant, J. Geophys. Res. 113 19, doi: 10.1029/2007jb005410.

Hartmann, J., and J. K. Levy (2005). Hydrogeological and gasgeochemical earthquake precursors - A review for application, Nat. Hazards 34 279-304.

Hatai, S., and N. Abe (1932). The Responses of the Catfish, Parasilurus Asotus, to Earthquakes, Proc. Imperial Acad. 8 375-378, doi: 10.2183/pjab1912.8.375.

Hayakawa, M., T. Asano, A. Schekotov, and H. Yamauchi (2016a). A study on the correlation of milk yield of cows with seismicity and ULF magnetic field variations, Open J. Earthquake Res. 05 206-218, doi: 10.4236/ojer.2016.54017. 
Hayakawa, M., H. Yamauchi, N. Ohtani, M. Ohta, S. Tosa, T. Asano, A. Schekotov, J. Izutsu, S. M. Potirakis, and K. Eftaxias (2016b). On the precursory abnormal animal behavior and electromagnetic effects for the Kobe earthquake (M 6) on April 12, 2013, Open J. Earthquake Res. 05 165-171, doi: 10.4236/ojer.2016.53013.

Hentig, H. v. (1923). Reactions of animals to changes in physical environment I. Animal and earthquake, J. Comp. Psychol. 61-71.

Ikeya, M., T. Komatsu, Y. Kinoshita, K. Teramoto, K. Inoue, M. Gondou, and T. Yamamoto (1997). Pulsed electric field before Kobe and Izu earthquakes from seismically-induced anomalous animal behavior (SAAB), Episodes 20 253-260.

Ingebritsen, S. E., and M. Manga (2014). Earthquakes: Hydrogeochemical precursors, Nat. Geosci. 7 697-698, doi: 10.1038/ngeo2261.

InternationalSeismologicalCentre (2014). On-line Bulletin I. S. Cent. (Editor), Thatcham, United Kingdom.

Jackson, D. D., and Y. Y. Kagan (2006). The 2004 Parkfield Earthquake, the 1985 Prediction, and Characteristic Earthquakes: Lessons for the Future, Bull. Seismol. Soc. Am. 96 S397-S409, doi: 10.1785/0120050821.

Jordan, T. H. (2006). Earthquake Predictability, Brick by Brick, Seismol. Res. Lett. 773.

Jordan, T. H., Y.-T. Chen, P. Gasparini, R. Madariaga, I. Main, W. Marzocchi, G. Papadopoulos, G. Sobolev, K. Yamaoka, and J. Zschau (2011). Operational Earthquake Forecasting: State of Knowledge and Guidelines for Utilization, Ann. Geophys. 54 315-391, doi: 10.4401/ag-5350.

Kanamori, H. (1977). The energy release in great earthquakes, J. Geophys. Res. 82 2981-2987, doi: 10.1029/JB082i020p02981.

Kant, I. M. (1756). Von den Ursachen der Erderschütterungen bei Gelegenheit des Unglückes, welches die westlichen Länder von Europa gegen das Ende des vorigen Jahres betroffen hat (1756), Berlin.

Kato, A., K. Obara, T. Igarashi, H. Tsuruoka, S. Nakagawa, and N. Hirata (2012). Propagation of Slow Slip Leading Up to the 2011 M-w 9.0 Tohoku-Oki Earthquake, Science 335 705-708, doi: 10.1126/science.1215141.

Kelman, I., R. Spence, J. Palmer, M. Petal, and K. Saito (2008). Tourists and disasters: lessons from the 26 December 2004 tsunamis, J. Coast. Conserv. 12 105-113, doi: 10.1007/s11852-008-0029-4.

Kerr, R. A. (2011). A Quake May Have Hinted That It Was on the Way, Science 331 836, doi: 10.1126/science.331.6019.836.

King, G. C. P., R. S. Stein, and J. Lin (1994). Static Stress Changes and the Triggering of Earthquakes, Bull. Seismol. Soc. Am. 84 935-953.

Kirschvink, J. L., M. Winklhofer, and M. M. Walker (2010). Biophysics of magnetic orientation: strengthening the interface between theory and experimental design, J. R. Soc. Interface 7 S179-S191, doi: 10.1098/rsif.2009.0491.focus.

Knuts, E., K. G. Hinzen, S. K. Reamer, and T. Camelbeeck (2017). A Nineteenth-Century National Prussian Macroseismic Questionnaire, Seismol. Res. Lett. 89 191-201, doi: 10.1785/0220170199.

Kossobokov, V. (2013). Earthquake prediction: 20 years of global experiment, Nat. Hazards 69 1155-1177, doi: 10.1007/s11069-012-0198-1.

Langbein, J., R. Borcherdt, D. Dreger, J. Fletcher, J. L. Hardebeck, M. Hellweg, C. Ji, M. Johnston, J. R. Murray, R. Nadeau, M. J. Rymer, and J. A. Treiman (2005). Preliminary report on the 28 September 2004, M 6.0 Parkfield, California earthquake, Seismol. Res. Lett. 76 10-26.

Lawson, A. C., and H. F. Reid (1910). The California Earthquake of April 18, 1906, J. Geol. 18 288-290.

Lecocq, T., Rapagnani, G., Martin, H., De Vos, F., Hendrickx, M., Van Camp, M., Vanneste, K., Camelbeeck, T. (2009). B-FEARS: The Belgian Felt Earthquake Alert and Report System, Cahiers du Centre Européen de Géodynamique et de Séismologie, doi:

Li, J. Z., Z. Q. Bai, W. S. Chen, Y. Q. Xia, Y. R. Liu, and Z. Q. Ren (2003). Strong earthquakes can be predicted: A multidisciplinary method for strong earthquake prediction, Nat. Hazards Earth Syst. Sci. 3 703-712.

Li, Y., Y. Liu, Z. Jiang, J. Guan, G. Yi, S. Cheng, B. Yang, T. Fu, and Z. Wang (2009). Behavioral change related to Wenchuan devastating earthquake in mice, Bioelectromagnetics 30 613-620, doi: 10.1002/bem.20520.

Lighton, J. R., and F. D. Duncan (2005). Shaken, not stirred: a serendipitous study of ants and earthquakes, J. Exp. Biol. 208 3103-7, doi: 10.1242/jeb.01735. 
Lindberg, R. G., D. D. Skiles, and P. Hayden (1981). Can animals predict earthquakes? A search for correlations between changes in activity patterns of two fossorial rodents and subsequent seismic events, in Open-File Report - U. S. Geological Survey, 37, doi:

Lomnitz, C. (1994). Fundamentals of earthquake prediction, Wiley, 344.

Lott, D. F., B. L. Hart, K. L. Verosub, and M. W. Howell (1979). Is unusual animal behavior observed before earthquakes? Yes and no, Geophys. Res. Lett. 6 685-687, doi: 10.1029/GL006i009p00685.

Lu, S., B. Qu, Y. Cai, M. Zhang, X. Zhao, R. Zhao, C. Yu, and B. Li (2015). Statistical analysis of the relationship between macroscopic anomalies and earthquakes, Earthquake Res. China 29 539-553.

Mallet, R. (1862). The great Neapolitan Earthquake of 1857, Chapman and Hall, London, 399.

Martinelli, G. (2000). Contributions to a History of Earthquake Prediction Research, Seismol. Res. Lett. 71 583-588.

McClellan, P. H. (1980). Preearthquake animal behavior; a closer look for alternative causes, Geophys. Res. Lett. 7 333-336, doi: 10.1029/GL007i005p00333.

Michael, A. J., and J. Langbein (1993). Earthquake prediction lessons from Parkfield experiment, Eos 145-155..

Mogi, K. (1986). Recent Earthquake Prediction Research in Japan, Science 233 324-330, doi: 10.1126/science.233.4761.324.

Mott, M. (2005). Did animals sense tsunami was coming?, in National Geographic, doi:

Nikonov, A. A. (1992). Abnormal animal behavior as a precursor of the 7 December 1988 Spitak, Armenia, earthquake, Nat. Hazards 6 1-10.

Nikonov, A. A. (1996). Biological precursors of the 1927 Crimean earthquake, Dokl. Earth Sci. 340 1-4.

Nur, A. (1972). Dilatancy, pore fluids, and premonitory variations of ts/tp travel times, Bull. Seismol. Soc. Am. 62 1217-1222..

Ohnaka, M. (1992). Earthquake source nucleation: A physical model for short-term precursors, Tectonophysics 211 149-178, doi: 10.1016/0040-1951(92)90057-D.

Ohnaka, M. (2000). A physical scaling relation between the size of an earthquake and its nucleation zone size, Pure Appl. Geophys. 157 2259-2282, doi: 10.1007/pl00001084.

Ohnaka, M. (2013). The Physics of Rock Failure and Earthquakes, Cambridge University Press, Cambridge, 270.

Omori, F. (1923). Pheasant as Seismoscope, Bull. Jap. Imp. Earthq. Investig. Comm. 11 1-5.

Oprsal, I., and L. Eisner (2014). Cross-correlation—an objective tool to indicate induced seismicity, Geophys. J. Int. 196 1536-1543, doi: 10.1093/gji/ggt501.

Orihara, Y., M. Kamogawa, and T. Nagao (2014). Preseismic Changes of the Level and Temperature of Confined Groundwater related to the 2011 Tohoku Earthquake, Sci. Rep. 4 6, doi: 10.1038/srep06907.

Ouzounov, D., N. Bryant, T. Logan, S. Pulinets, and P. Taylor (2006). Satellite thermal IR phenomena associated with some of the major earthquakes in 1999-2003, Phys. Chem. Earth. 31 154-163, doi: 10.1016/j.pce.2006.02.036.

Papazachos, B. C., E. Scordilis, M., D. G. Panagiotopoulos, C. B. Papazachos, and G. F. Karakaisis (2004). Global relations between seismic fault parameters and moment magnitude of earthquakes, Bull. Geol. Soc.Greece XXXVI 1482-1489.

Park, S. K., M. J. S. Johnston, T. R. Madden, F. D. Morgan, and F. F. Morrison (1993). Electromagnetic precursors to earthquakes in the ULF band: a review of observations and mechanisms, Rev. Geophys. 31 117-32.

Popper, K. (1935). Logik der Forschung, Springer-Verlag, Wien, 248.

Pulinets, S., and D. Ouzounov (2011). Lithosphere-Atmosphere-Ionosphere Coupling (LAIC) model - An unified concept for earthquake precursors validation, J. Asian Earth Sci. 41 371-382, doi: 10.1016/j.jseaes.2010.03.005.

Reasenberg, P. A. (1999). Foreshock occurrence before large earthquakes, J. Geophys. Res. 104 4755-4768, doi: 10.1029/1998jb900089.

Richon, P., J. C. Sabroux, M. Halbwachs, J. Vandemeulebrouck, N. Poussielgue, J. Tabbagh, and R. Punongbayan (2003). Radon anomaly in the soil of Taal Volcano, the Philippines; a likely precursor of the M 7.1 Mindoro earthquake (1994), Geophys. Res. Lett. 30 doi.

Rikitake, T. (1975). Earthquake precursors, Bull. Seismol. Soc. Am. 65 1133-1162. 
Rikitake, T. (1978). Biosystem behaviour as an earthquake precursor, Tectonophysics 51 1-20, doi: 10.1016/00401951(78)90048-3.

Rikitake, T. (1994). Nature of macro-anomaly precursory to an earthquake, J. Phys. Earth 42 149-63.

Rikitake, T., and I. Kayano (1993). Macro-Anomalies Precursory to the 1984 Naganoken Seibu, Japan, Earthquake of Magnitude 6.8 -Possibility of Assessing the Epicenter, Magnitude and Occurrence Time, J. Phys. Earth 41 305-317.

Roeloffs, E., and J. Langbein (1994). The earthquake prediction experiment at Parkfield, California, Rev. Geophys. 32 315-336..

Roeloffs, E. A. (1988). Hydrologic precursors to earthquakes: a review, Pure Appl. Geophys. 126 177-209.

Scholz, C. H., L. R. Sykes, and Y. P. Aggarwal (1973). Earthquake prediction: a physical basis, Science $181803-$ 810., doi: 10.1126/science.181.4102.803.

Schorlemmer, D., and M. C. Gerstenberger (2007). RELM Testing Center, Seismol. Res. Lett. 78 30, doi: 10.1785/gssrl.78.1.30.

Schorlemmer, D., M. C. Gerstenberger, S. Wiemer, D. D. Jackson, and D. A. Rhoades (2007). Earthquake Likelihood Model Testing, Seismol. Res. Lett. 78 17, doi: 10.1785/gssrl.78.1.17.

Schurr, B., G. Asch, S. Hainzl, J. Bedford, A. Hoechner, M. Palo, R. J. Wang, M. Moreno, M. Bartsch, Y. Zhang, O. Oncken, F. Tilmann, T. Dahm, P. Victor, S. Barrientos, and J. P. Vilotte (2014). Gradual unlocking of plate boundary controlled initiation of the 2014 Iquique earthquake, Nature 512 299, doi: 10.1038/nature13681.

Sidorin, A. Y. (2003). Search for earthquake precursors in multidisciplinary data monitoring of geophysical and biological parameters, Nat. Hazards Earth Syst. Sci. 3 153-158.

Skelton, A., M. Andren, H. Kristmannsdottir, G. Stockmann, C.-M. Morth, A. Sveinbjornsdottir, S. Jonsson, E. Sturkell, H. R. Gurunardottir, H. Hjartarson, H. Siegmund, and I. Kockum (2014). Changes in groundwater chemistry before two consecutive earthquakes in Iceland, Nat. Geosci. 7 752-756, doi: 10.1038/ngeo2250.

Smith, W. D. (1981). The b-value as an earthquake precursor, Nature 289 136-139, doi: 10.1038/289136a0.

Straser, V. (2013). A potential relationship between aimal behavior and pre-seismic signals in the North Western Apennines (Italy), New Concepts in Global Tectonics Journal 111-16.

Sykes, L. R., B. E. Shaw, and C. H. Scholz (1999). Rethinking earthquake prediction, Pure Appl. Geophys. 155 207232, doi: 10.1007/s000240050263.

Thomas, D. (1988). Geochemical precursors to seismic activity, Pure Appl. Geophys. 126 241-266.

Thomas, J. N., J. Huard, and F. Masci (2017). A statistical study of global ionospheric map total electron content changes prior to occurrences of $M \geq 6.0$ earthquakes during 2000-2014, Journal of Geophysical Research -A: Space Physics 122 2151-2161, doi: 10.1002/2016JA023652.

Tomoda, Y. (1998). Day to day variation in catch of fish and seismic activity, Proc. Japan Acad. 74 179-184.

Toutain, J. P., and J. C. Baubron (1999). Gas geochemistry and seismotectonics: a review, Tectonophysics 304 1-27.

Tributsch, H. (1978). Wenn die Schlangen erwachen: mysteriöse Erdbebenvorzeichen; endlich ernstgenommene Naturphänomene führen zu einem Frühwarnsystem, Deutsche Verlags-Anstalt, 272.

Tsuruoka, H., N. Hirata, D. Schorlemmer, F. Euchner, K. Z. Nanjo, and T. H. Jordan (2012). CSEP Testing Center and the first results of the earthquake forecast testing experiment in Japan, Earth, Planets and Space 64 661-671, doi: 10.5047/eps.2012.06.007.

Turcotte, D. L. (1991). Earthquake Prediction, Annu. Rev. Earth Planet. Sci. 19 263-281, doi: 10.1146/annurev.ea.19.050191.001403.

Uyeda, S., T. Nagao, and M. Kamogawa (2009). Short-term earthquake prediction: Current status of seismoelectromagnetics, Tectonophysics 470 205-213, doi: 10.1016/j.tecto.2008.07.019.

van Noten, K., Lecocq, T., Sira, C., Hinzen, K.-G., Camelbeeck, T. (2017). Path and site effects deduced from merged transfrontier internet macroseismic data of two recent M4 earthquakes in northwest Europe using a grid cell approach, Solid Earth 8 453-477, doi: 10.5194/se-8-453-2017.

Varnes, D. J. (1989). Predicting earthquakes by analyzing accelerating precursory seismic activity, Pure Appl. Geophys. 130 661-686, doi: 10.1007/BF00881603.

Wang, K., Q.-F. Chen, S. Sun, and A. Wang (2006). Predicting the 1975 Haicheng Earthquake, Bull. Seismol. Soc. Am. 96 757-795, doi: 10.1785/0120050191. 
Wells, D. L., and K. J. Coppersmith (1994). New empirical relationships among magnitude, rupture length, rupture width, rupture area, and surface displacement, Bull. Seismol. Soc. Am. 84 974-1002.

Whitehead, N. E., and Ü. Ulusoy (2013). Macroscopic anomalies before the September $2010 \mathrm{M}=7.1$ earthquake in Christchurch, New Zealand, Nat. Hazards Earth Syst. Sci. 13 167-176, doi: 10.5194/nhess-13-167-2013.

Whitehead, N. E., U. Ulusoy, H. Asahara, and M. Ikeya (2004). Are any public-reported earthquake precursors valid?, Nat. Hazards Earth Syst. Sci. 4 463-468.

Wikramanayake, E., P. Fernando, and P. Leimgruber (2006). Behavioral response of satellite-collared elephants to the tsunami in southern Sri Lanka, Biotropica 38 775-777, doi: 10.1111/j.1744-7429.2006.00199.x.

Woith, H. (2015). Radon earthquake precursor: A short review, Eur. Phys. J. Spec. Top. 224 611-627, doi: 10.1140/epjst/e2015-02395-9.

Wood, H. O. (1911). The Observation of Earthquakes - a Guide for the general Observer, Bull. Seismol. Soc. Am. 2 48-82.

Wyss, M. (1979). Estimating maximum expectable magnitude of earthquake from fault dimensions, Geology 7 336340, doi: 10.1130/0091-7613(1979)7<336:EMEMOE>2.0.CO;2.

Wyss, M. (1991). Evaluation of proposed earthquake precursors, American Geophysical Union, Washington D.C., 94.

Wyss, M. (1997). Second round of evaluations of proposed earthquake precursors, Pure Appl. Geophys. 149 3-16, doi: 10.1007/BF00945158.

Wyss, M. (2001). Why is earthquake prediction research not progressing faster?, Tectonophysics 338 217-223.

Wyss, M., and R. E. Habermann (1988). Precursory seismic quiescence, Pure Appl. Geophys. 126 319-332, doi: 10.1007/BF00879001.

Wyss, M., and Z. Wu (2014). How Many Lives were Saved by the Evacuation before the M 7.3 Haicheng Earthquake of 1975?, Seismol. Res. Lett. 85 126-129.

Yamauchi, H., M. Hayakawa, T. Asano, N. Ohtani, and M. Ohta (2017). Statistical Evaluations of Variations in Dairy Cows' Milk Yields as a Precursor of Earthquakes, Animals 7 doi: 10.3390/ani7030019.

Yamauchi, H., H. Uchiyama, N. Ohtani, and M. Ohta (2014). Unusual animal behavior preceding the 2011 earthquake off the pacific coast of Tohoku, Japan: A way to predict the approach of large earthquakes, Animals 4 131-145, doi: 10.3390/ani4020131.

Yokoi, S., M. Ikeya, T. Yagi, and K. Nagai (2003). Mouse circadian rhythm before the Kobe earthquake in 1995, Bioelectromagnetics 24 289-291, doi: 10.1002/bem.10108.

Yosef, R. (2010). Reactions of birds to an earthquake, Bird Study 44 123-124, doi: 10.1080/00063659709461047. 


\title{
SUPPLEMENTARY MATERIAL
}

\section{Can animals predict earthquakes?}

\author{
Heiko Woith, Gesa M. Petersen, Sebastian Hainzl, Torsten Dahm
}

The supplementary material gives a brief overview about nearly 200 publications related to precursory animal behavior, which have been exploited during the review process. It should be stressed that most of the publications contain claims, which are not substanciated by rigorous testing. Nevertheless, we decided not to repeat the word "claimed" 200 times in the following paragraphs, but merely report and sometimes comment on the claims itself. The material is structured in 8 chapters: (1) reviews, (2) timeseries, (3) experiments, (4) interviews, (5) conferences, (6) myths, (7) animals, and (8) mechanisms.

\section{Reviews}

Many review articles were published about abnormal behavior of animals before earthquakes (Allen, 1976; Bhargava et al., 2009; Bhattacharyya, 2016; Buskirk et al., 1981; Deshpande, 1986; Fu and Weng, 2010; Grant and Conlan, 2013; Harnett, 2012; Hentig, 1923; Ikeya, 2004; Jiang, 1980; Kerr, 1980; Kirschvink, 2000; Kirschvink et al., 2010; Lakshmi et al., 2014; Logan, 1977; Lowry, 1983; Reasenberg, 1978; Rikitake, 1978; Rikitake, 2001; Rikitake et al., 1993; Schaal, 1988; Schnytzer and Schnytzer, 2011; Tong, 1988; Tributsch, 1978b, 1984, 2005, 2013a).

- 28 reviews (of 200 exploited publications)

- $\quad$ at the age of 17, Harnett (2012) interviewed renowned scientists and prepared a short, but concise review on the potential of animals to aid earthquake prediction

- $\quad$ most cited: Buskirk et al. (1981), Kirschvink (2000), and Tributsch (1978b)

\section{Timeseries}

14 timeseries are presented in 12 publications (Berberich et al., 2013; Deshcherevskii and Sidorin, 2004; Feng and Jiang, 1992; Grant and Halliday, 2010; Hayakawa et al., 2016a, 2016b; Li et al., 2003; Li et al., 2009; Lindberg et al., 1981; Sidorin, 2003; Straser, 2013; Yamauchi et al., 2014; Yokoi et al., 2003).

Examples are:

Yamauchi et al. (2017) statistically evaluated daily variations of dairy cow’s milk yield during one year. A milk yield timeseries of one year is presented, the potential influence of 32 earthquakes is discussed, but the allocation of anomalies and earthquakes was not specified - and thus this case study could not enter our evaluation.

A timeseries of the catch of horse mackerel in Japan is shown by Tomoda (1998). During seismic swarms preceding the great Izu earthquake of 1930 the catch increased significantly. A post-seismic drop of the daily catch of fish is described by Tweddle and Crossley (1991). In sum:

- $\quad$ only very few timeseries exist $(n=14)$

- observation times are short, the longest timeseries has a length of about 1 year.

Descriptions of co- and post seismic animal response to earthquakes are few, none of them presenting a timeseries (Chan et al., 2013; Galassi et al., 2014; Ganguly, 2009; Kario et al., 2003; Petrazzi et al., 2010; Snarr, 2005; Tan et al., 2009; Yosef, 1997, 2010). 


\section{Experiments}

Laboratory and a few field experiments were described (Chen et al., 2010; Deshcherevskii and Sidorin, 2004; Feng, 1992; Ferasyi et al., 2013; Grant and Conlan, 2015; Hatai and Abe, 1932; Ikeya et al., 1997, 1998a, 2000, 2004; Li et al., 2009; Lindberg et al., 1981; Liu et al., 2014; Montenegro et al., 1995; Nishimura et al., 2010; Otis and Kautz, 1980; Otis et al., 1985; Straka et al., 2015; Xu and Jiang, 1989; Yanai et al., 2012). USGS conducted combined lab and field experiments in the 1970s (Lindberg et al., 1981; Otis and Kautz, 1980; Otis et al., 1985). Within the frame of an “integrated science education” project, a „catfish network” had been established in high schools in Japan aimed at studying daily to annual rythms in animal behavior and possible disturbances (Ikeya et al. 2004).

An integrated study on geophysical and biological anomalies before earthquakes in Austria and Indonesia was presented by Straka et al. (2015). Up to now, only one publication in Indonesian language could be found about first results of the project (Ferasyi et al., 2013).

Recently, seven farms with different animals have been established as seismic stations in Nanjing, Jiangsu province, China. One of them is an ecological garden in Yuhuatai district, containing 200 black boars, 2,000 chickens, and a 2 square kilometer fish pond. Cameras are installed around the animals' living environment to observe their behavior. Their feeders report to the seismological bureau twice a day on any abnormal behavior that professionals will analyze for whether a possible earthquake is imminent.

\section{Interviews}

The scientific value of interviews might be debated unless they are performed by professionals. Nevertheless, interview-based reports (Chen et al., 2000; Kelman et al., 2008; Lecocq, 2009; Lott et al., 1981; Nikonov, 1992; Sbarra et al., 2009; Sciarra et al., 2014; van Noten, 2017; Whitehead and Ulusoy, 2013; Whitehead et al., 2004) will become more frequent due to internet questionnaires in future.

Retrospective public-reported earthquake precursors related to the 1995 Kobe and 1999 Izmit and were statistically tested by Whitehead et al. (2004). The authors concluded that some of the claimed precursors reported within $90 \mathrm{~km}$ from the epicenter and within one day before the event might be valid. Similar findings (one day, $57 \mathrm{~km}$ ) were obtained from the analysis of 400 reports related to the 2010 M 7.1 Darfield earthquake, New Zealand (Whitehead and Ulusoy, 2013). In the nineteenth century the Prussian administration systematically conducted surveys similar to present-day macroseismic questionnaires to collect information about earthquakes. The early versions (starting in 1828) also contained questions related to animal behavior. Interestingly, these questions had been removed in 1877 after evaluating their usefulness (Knuts et al., 2017). Since 2002, the Royal Observatory of Belgium is collecting web-based questionnaires on felt reports after major earthquakes. Since 2010, this system is shared with the earthquake observatory at Bensberg, University of Cologne, Germany (Lecocq et al., 2009; van Noten et al., 2017). In 2013 the Italian INGV (Istituto Nazionale di Geofisica e Vulcanologia) developed and tested a questionnaire about anomalous geological and biological phenomena (Sciarra et al., 2014).

\section{Conferences}

A conference on animal behavior had been held by USGS in Menlo Park, California on 23-24 October 1976 (Evernden, 1976; Logan, 1977; Reasenberg, 1978). One report at the conference dealt with long-term observations of chimpanzees at the Stanford Outdoor Primary Facility, located close to the San Andreas Fault zone (Kraemer et al., 1976). Several behavior parameters 
like activity and the position of the animals were routinely observed in order to study long-term changes due to maturation and hormonal changes. A group of chimpanzees was daily chosen and each individual then observed for 30 minutes, recording the behavior every 30 seconds. The presented time series lasts from May until July 1975. At least eight hours prior to an earthquake swarm $(M<3.1)$ located about $6 \mathrm{~km}$ SW of the facility on 19-24 June 1975, as well as prior to one single event on 24 July 1975, changes in the activity pattern were observed. However, the observation day prior to the swarm coincides with an exceptionally low sample number and is therefore the weakest data point, and restless behavior also occurred on other days, and was often associated with environmental disturbances. The authors suggest a link between the earthquake swarm and an enhanced activity, but also point out that a longer time series, a denser sampling and more animal groups would be needed to found the relationship. Furthermore, they suggest that baseline levels of behavior measure must be defined and generally studies must be conducted in stable living environments.

\section{Myths}

In ancient Japan the people thought that earthquakes were caused by catfish moving underground (Smits, 2006, 2014). Thus, it is not surprising that many reports about abnormal animal behavior are related to fish. Nunn (2014) examined myth in the Asia-pacific region claiming that these tales can lead to an improved understanding of geohazards.

Escaping gas called "pneuma" in ancient earthquake concepts is reviewed by Tributsch (2013b) in relation to animal, atmospheric and thermal precursors. The list of curiosities could be continued, but this is beyond the scope of this review. The reader is referred to an article about geomythodology by Vitaliano (2007) for further reading. We want to make the point that myths tell likely more about human psychology, than about the preparation of an earthquake.

\section{Animals}

The majority of reported anomalies refer to mammals, followed by fish, and birds (Fig. S1). There are regional differences, e.g. in Japan most precursors are reported related to the behavior or catchment of fish.

\subsection{Mammals}

\subsubsection{Humans}

An abnormal rate of early wakening before the 1995 Kobe Earthquake was postulated from interviews of school children by Ikeya and Whitehead (2013). The wake-up ratio decreased with epicentral distance. Social tension as precursor of large earthquakes was discussed by Molchanov (2008).

Co- and postseismic effects of earthquakes on human health (heart rate, blood pressure, stress, birth defects) were reported (Chan et al., 2013; Kario et al., 2003; Petrazzi et al., 2010; Sakakibara et al., 2016; Straser, 2013; Tan et al., 2009).

\subsubsection{Cats, Dogs}

Many anecdotal reports refer to cats and dogs. Only a few case studies were described (de Liso and Fidani, 2014; de Liso et al., 2014a, 2014b; Lutz, 1921; Ma and Chen, 2013; Yamauchi et al., 2014). 


\subsubsection{Cows}

Fidani et al. (2014) reported the case of a herd of cows leaving the hill pasture and descending near to the village two days before a strong earthquake. The milk yield of dairy cows has been investigated in Japan (Hayakawa et al., 2016a; Yamauchi et al., 2014, 2017).

\subsection{4 $\underline{\text { Horses }}$}

Codazza and Martinelli (1993) discussed the sensitivity of horses to electromagnetic field changes.

\subsubsection{Elephants}

Contrary to anecdotal evidence, elephants ranging close to the tsunami impact area in Sri Lanka did not show any unusual behavior allowing an early detection of the approaching tsunami (Garstang, 2009; Wikramanayake et al., 2006).

\subsubsection{Rodents (Mice, Rats)}

Freefield and lab experiments on rodents were carried out by USGS scientists already in the 1970s (Gawthrop et al., 1976; Lindberg et al., 1981). Laboratory studies related to the disturbance of the circadian rhythm of mice before earthquakes were reported from China and Japan (Li et al., 2009; Yokoi et al., 2003).

Earthquake-induced stress on mice were investigated (Liu et al., 2014; Montenegro et al., 1995;

Xu and Jiang, 1989; Yanai et al., 2012).

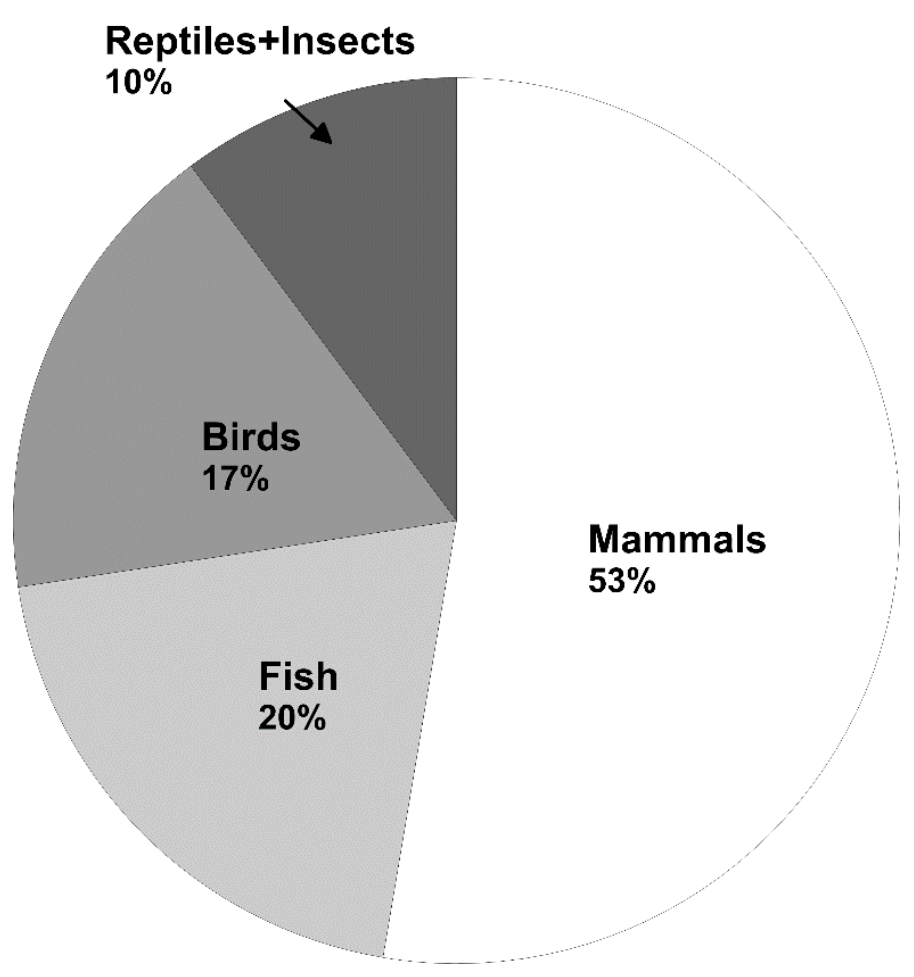

Figure S1. Number of animal precursor for different animal categories. The percentages refer to a total number of 792 reports.

\subsection{Birds}

Behavioral changes of budgerigars before earthquakes were reported (Chen et al., 2013; Feng and Jiang, 1992; Li, 1989, 2008; Li et al., 2003). Reactions of birds to earthquakes were described by Yosef (1997, 2010). At first glance, this looks like an example of a poorly founded hypothesis, 
since birds live in the air and have nothing to fear from earthquakes. Why would they learn to avoid negative impacts from earthquakes, if there are none? In fact, many reports refer to chickens or pheasants, which live on the ground most of the time and might sense seismic waves (see e.g. Omori, 1923).

\subsection{Insects}

Ants were studied (Akhoondzadeh, 2015; Apostol et al., 2016; Berberich et al., 2013; Berberich and Schreiber, 2013; Lighton and Duncan, 2005), and laboratory experiments with silkworms were performed by Ikeya et al. (1998b).

\section{$7.4 \quad$ Reptiles}

Toad migration patterns were claimed to be a precursor to the L'Aquila 2009 earthquake (Grant and Halliday, 2010). Contrary, a global analysis of frog swarms revealed that most frog activities were not related to earthquakes (Grant and Conlan, 2013). Observations of abnormal behavior of snakes were reported by Ikeya (2004), and Tributsch (1984).

\subsection{Fish}

Various studies report on abnormal behavior of fish (Deshcherevskii and Sidorin, 2004; Ferasyi et al., 2013; Frohlich and Buskirk, 1980; Heupel et al., 2003; Sidorin, 2003; Suyehiro, 1934; Tomoda, 1998; Tweddle and Crossley, 1991).

A correlation between catch of fish and seismic swarm activity was found in Japan (Tomoda, 1998) and Lake Malawi (Tweddle and Crossley, 1991). Catfish has been studied under experimental conditions in Japan (Hatai and Abe, 1932; Ikeya et al., 1998a; Smits, 2006, 2014).

\section{Mechanisms}

Excellent reviews of possible sensory mechanisms were given by Buskirk et al. (1981), and Kirschvink (2000). Some authors argue that animals have a "sixth sense" to predict earthquakes. According to Tributsch (1978b) this seems unlikely, because different animal groups show abnormal behavior before an upcoming event - although their sensory capabilities differ. Tributsch (1978b) reviewed the sensory inventory of animal groups and concluded that only electrical fields, specifically fast field changes and long-periodic electromagnetic radiation might affect birds, mammals, and fish equally well. Similar electrical phenomena occur during thunder storms. From this it was concluded that aerosols might play a key role in unusual animal behavior (Griffiths and DeCosemo, 1994; Hoenig, 1979; Krueger and Reed, 1976; Tributsch, 1978a). Ikeya (2004) promotes electro-magnetic effects. A hypothesis has been formulated that the hormonal balance, e.g. serotonin levels, might be disturbed by various physical processes (Chen et al., 2010; Singh and Singh, 2012).

\subsection{Acoustic waves}

Acoustic waves generated by (before) earthquakes may explain unsual animal behavior (Astuti et al., 2011; Bhargava et al., 2011; Kelley and Garstang, 2013; Shi, 1986; Stierman, 1980).

\subsection{Aerosols, ionization, positive holes}

The effect of aerosols, and air ionization were repeatedly proposed as a potential source for abnormal animal behavior (Freund and Stolc, 2013; Freund et al., 2009; Grant et al., 2011; Griffiths and DeCosemo, 1994; Hoenig, 1979; Krueger and Reed, 1976; Tributsch, 1978a). 


\subsection{Electric fields}

Electric fields might play a role to explain abnormal animal behavior (Bleier et al., 2010; Bufe and Nanevicz, 1976; Dologlou, 2010; Hayakawa, 2013; Ikeya et al. 1996a, 1996b, 2000, 2004; Katsika-Tsigourakou, 2012; Kopytenko et al., 1995; Nishimura et al., 2010; Panagopoulos et al., 2000, 2002; Philippetis, 2009).

\subsection{Gases (Ozone, $\mathrm{H}_{2} \mathrm{~S}$ )}

The potential role of gases is discussed by Baragiola et al. (2011), Cain et al. (2007), and Ganguly (2009). During crushing and grinding of rocks up to $10 \mathrm{ppm}$ ozone were generated according to Baragiola et al. (2011). The effect of $\mathrm{H}_{2} \mathrm{~S}$ on animals has been studied by Feng (1992).

\subsection{Gravity}

Akhmedov (2015) proposed "gravitational receptors” which each and every animal possesses.

\subsection{Ground shaking}

The response of animals to $V_{p}$ and $V_{s}$ has been discussed by Kirschvink (2000).

\subsection{Groundwater chemistry $\mathrm{H}_{2} \mathrm{O}_{2}$}

Based on Friedemann Freund's hypothesis, $\mathrm{H}_{2} \mathrm{O}_{2}$ (hydrogen peroxide) might be generated before earthquakes at rock-water interfaces (Freund and Stolc, 2013; Grant et al., 2011; KatsikaTsigourakou, 2012). The effect could be demonstrated under lab conditions, but it will be difficult to proof via field measurements, because $\mathrm{H}_{2} \mathrm{O}_{2}$ is very reactive and decays within hours after its generation (Balk et al., 2009).

\subsection{Meteorological effects}

Meteorological effects may play a significant role to cause abnormal animal behavior according to the following authors: (Liu et al., 2010; McClellan, 1980; Nienaber et al., 1999; Segnalini et al., 2013). Based on a retrospective study of abnormal animal behavior Lott et al. (1979) concluded from 50 interviews that the M4.7 Willits earthquake (22 November 1977) in California had been preceded by abnormal animal behavior. McClellan (1980) pointed out that 3 external factors might have influenced the animal behavior, namely (i) heavy rainfall and flooding, (ii) large barometric pressure variations, and (iii) enhanced solar-flare cosmic radiation. In scientific hypothesis testing, meteorological effects like the ones listed above are sources of noise.

\subsection{Magnetics}

Although no convincing precursory changes of the magnetic field have observed to date, the influence of the magnetic field has been discussed in the context of animal behavior (Cai and Plenio, 2013; Kattnig et al., 2016; Kirschvink, 2014; Kirschvink et al., 2010; Ritz, 2011; Ritz et al., 2010; Weaver et al., 2000).

\subsection{Neurotransmitter}

Physiological changes (neurotransmitter) were investigated (Chen et al., 2010; Hussain and Asif, 2012; Medici et al., 1985; Singh and Singh, 2012).

\section{Data and Resources}

All data used in this paper came from published sources listed in the references. The information about seven farms with different animals established as seismic stations in Nanjing, Jiangsu province, China was obtained from http://www.earthquakepredict.com/2016/07/animals-areofficially-earthquake.html. 


\section{References}

Akhmedov, T. R. (2015). Bio-Precurosrs of earthquakes and their possible mechanism, Progr. Phys. 11 38-39.

Akhoondzadeh, M. (2015). Ant Colony Optimization detects anomalous aerosol variations associated with the Chile earthquake of 27 February 2010, Adv. Space Res. 55 1754-1763, doi: 10.1016/j.asr.2015.01.016.

Allen, C. R. (1976). The role of animal behavior in the Chinese earthquake-prediction program, in Abnormal animal behavior prior to earthquakes J. F. Evernden (Editor), USGS, Menlo Park, CA, 5-13.

Apostol, A., T. Moldoveanu, A. Sarlea, and T. Victorin (2016). Can Red Wood Ants Predict Earthquakes?, J. Earth Sci. 2 1-10.

Astuti, W., A. M. Aibinu, M. J. E. Salami, R. Akmelawati, and A. G. A. Muthalif (2011). Animal sound activity detection using multi-class support vector machines.

Balk, M., M. Bose, G. Ertem, D. A. Rogoff, L. J. Rothschild, and F. T. Freund (2009). Oxidation of water to hydrogen peroxide at the rock-water interface due to stress-activated electric currents in rocks, Earth Planet. Sci. Lett. 283 87-92, doi: 10.1016/j.epsl.2009.03.044.

Baragiola, R. A., C. A. Dukes, and D. Hedges (2011). Ozone generation by rock fracture: Earthquake early warning?, Appl. Phys. Lett. 99 204101, doi: 10.1063/1.3660763.

Berberich, G., M. Berberich, A. Grumpe, C. Wohler, and U. Schreiber (2013). Early results of three-year monitoring of Red Wood Ants' behavioral changes and their possible correlation with earthquake events, Animals 3 63-84, doi: 10.3390/ani3010063.

Berberich, G., and U. Schreiber (2013). GeoBioScience: Red Wood Ants as Bioindicators for Active Tectonic Fault Systems in the West Eifel (Germany), Animals 3 63-84, doi: 10.3390/ani3020475.

Bhargava, N., V. K. Katiyar, M. L. Sharma, and P. Pradhan (2009). Earthquake prediction through animal behavior: A review, Indian Journal of Biomechanics 78159165.

Bhargava, N., P. Pradhan, V. K. Katiyar, and M. L. Sharma (2011). Unusual animal behavior due to acoustic waves generated by an earthquake, Journal of International Academy of Physical Sciences 15 435-445.

Bhattacharyya, M. (2016). Earthquake prediction by animals: A review of Seismic Anomalous Animal Behaviour (SAAB), Ecology, Environment and Conservation 22 235-243.

Bleier, T., C. Dunson, C. Alvarez, F. Freund, and R. Dahlgren (2010). Correlation of pre-earthquake electromagnetic signals with laboratory and field rock experiments, Nat. Hazards Earth Syst. Sci. 10 1965-1975, doi: DOI 10.5194/nhess-10-1965-2010.

Bufe, C. G., and J. Nanevicz (1976). Atmospheric electric field observations, animal behavior, and earthquakes, in Open File Rep. US Geol. Surv.. 76-876.

Buskirk, R. E., C. Frohlich, and G. V. Latham (1981). Unusual animal behavior before earthquakes; a review of possible sensory mechanisms, Rev. Geophys. Space Phys. 19 247-270, doi: 10.1029/RG019i002p00247.

Cai, J., and M. B. Plenio (2013). Chemical compass model for avian magnetoreception as a quantum coherent device, Phys. Rev. Lett. 111 230503, doi: 10.1103/PhysRevLett.111.230503.

Cain, W. S., R. Schmidt, and P. Wolkoff (2007). Olfactory detection of ozone and D-limonene: reactants in indoor spaces, Indoor Air 17 337-47, doi: 10.1111/j.1600-0668.2007.00476.x.

Chan, C., J. Elliott, R. Troughton, C. Frampton, D. Smyth, I. Crozier, and P. Bridgman (2013). Acute myocardial infarction and stress cardiomyopathy following the Christchurch earthquakes, PLos One 8 e68504, doi: 10.1371/journal.pone.0068504.

Chen, A. T., T. Ouchi, A. M. Lin, J. C. Chen, and T. Maruyama (2000). Phenomena associated with the 1999 ChiChi earthquake in Taiwan, possible precursors and after effects, Terr. Atmos. Ocean Sci. 11 689-700.

Chen, L. L., X. Hu, J. Zheng, H. H. Zhang, W. Kong, W. H. Yang, T. S. Zeng, J. Y. Zhang, and L. Yue (2010). Increases in energy intake, insulin resistance and stress in rats before Wenchuan earthquake far from the epicenter, Exp. Biol. Med. 235 1216-23, doi: 10.1258/ebm.2010.010042.

Chen, W. S., J. Z. Li, C. Y. Liu, Y. Q. Xia, and H. Q. Chen (2013). Abnormal signals before Wenchuan and Yushu earthquakes, Beijing Gongye Daxue Xuebao / Journal of Beijing University of Technology 39 1505-1508.

Codazza, D., and G. Martinelli (1993). Sistemi biogeoelettromagnetici Sinergici: Possibilità Sensorie del Cavallo nel Monitoraggio dei Fenomeni Precursori degli Eventi Tellurici e delle Modificazioni ambientali nel Comprensorio Irpino-Lucano, Veterinaria Italiana 29 36-41. 
de Liso, G., and C. Fidani (2014). Seismic precursory phenomenology in unusual animal behaviour in Val Pellice, Western Piedmont, in comparison with anomalies of some physical parameters, Open J. Earthquake Res. 03 3042, doi: 10.4236/ojer.2014.31005.

de Liso, G., C. Fidani, and A. Viotto (2014a). Multi-parametric monitoring system of associated seismic phenomenology and unusual animal behaviour in Western Piedmont, Adv. Res. 2 303-319.

de Liso, G., C. Fidani, and A. Viotto (2014b). Unusual animal behaviour before earthquakes and multiple parameter monitoring in Western Piedmont, Earth Sci. 3 14-25, doi: 10.11648/j.earth.20140301.13.

Deshcherevskii, A. V., and A. Y. Sidorin (2004). Changes in the behavior of fishes and insects before earthquakes at the Garm test site, Dokl. Earth Sci. 399 1172-1176.

Deshpande, B. G. (1986). Earthquakes, animals and man capter III - animal repsonse to earthquakes, Proc. Indian Natl. Sci. Acad. B Biol. Sci. B52 585-618.

Dologlou, E. (2010). Recent aspects on possible interrelation between precursory electric signals and anomalous bioeffects, Nat. Hazards Earth Syst. Sci. 10 1951-1955, doi: 10.5194/nhess-10-1951-2010.

Evernden, J. F. (1976). Abnormal animal behavior prior to earthquakes, I, U.S. Dept. of Commerce, National Technical Information Service.

Feng, C. (1992). Research on anomalous mechanism of animal behavior before earthquakes - biological effect of sulphurous ground gases (H2S), Earthquake (Beijing) 12 66-72.

Feng, C., and J. Jiang (1992). Quantitative observation and study on rhythmic abnormalities of activities in animals prior to earthquakes, Acta Seism. Sin. 5 857-865, doi: 10.1007/BF02651034.

Ferasyi, T. R., M. Sabri, H. Hamdani, A. Azhari, A. Amiruddin, E. Erwin, W. Straka, and R. Faber (2013). An indication of African catfish's (Larias Gariepinus) behavioral changes as a repsonse for increased seismic activity [indonesian], Jurnal Natural 13 1-5 (indonesian), doi: 10.17969/jn.v13i1.837.

Fidani, C., F. Freund, and R. Grant (2014). Cows Come Down from the Mountains before the (Mw $=6.1)$ Earthquake Colfiorito in September 1997; A Single Case Study, Animals 4 292, doi: 10.3390/ani4020292.

Freund, F., and V. Stolc (2013). Nature of Pre-Earthquake Phenomena and their Effects on Living Organisms, Animals 3 513, doi: 10.3390/ani3020513.

Freund, F. T., I. G. Kulahci, G. Cyr, J. Ling, M. Winnick, J. Tregloan-Reed, and M. M. Freund (2009). Air ionization at rock surfaces and pre-earthquake signals, J. Atmos. Sol. Terr. Phys. 71 1824-1834, doi: DOI 10.1016/j.jastp.2009.07.013.

Frohlich, C., and R. E. Buskirk (1980). Can fish detect seismic waves?, Geophys. Res. Lett. 7 569-572, doi: 10.1029/GL007i008p00569.

Fu, L., and Y. Weng (2010). The History and Revelation of Research of Abnormal Animal Behaviors before Earthquakes in China, Journal of Dialectics of Nature 32 78-85.

Galassi, D. M. P., P. Lombardo, B. Fiasca, A. Di Cioccio, T. Di Lorenzo, M. Petitta, and P. Di Carlo (2014). Earthquakes trigger the loss of groundwater biodiversity, Sci. Rep. 4 8, doi: 10.1038/srep06273.

Ganguly, N. D. (2009). Variation in atmospheric ozone concentration following strong earthquakes, Int. J. Remote Sens. 30 349-356, doi: 10.1080/01431160802282862.

Garstang, M. (2009). Precursor tsunami signals detected by elephants, Open Conservat. Biol. J. 3 1-3.

Gawthrop, W. H., M. Wyss, R. Johnson, and R. E. Habermann (1976). Preliminary experiments on the behavior of mice before rock failure in the laboratory, in National Earthquake Hazards Reduction Program, Conference I, Abnormal Animal Behavior Prior to Earthquakes I J. F. Evernden (Editor), US Dept. of the Interior Geological Survey, Menlo Park, 205-211.

Grant, R., and H. Conlan (2013). Frog swarms: Earthquake precursors or false alarms?, Animals 3 962, doi: 10.3390/ani3040962.

Grant, R., and H. Conlan (2015). Behavioral Response of Invertebrates to Experimental Simulation of Pre-Seismic Chemical Changes, Animals 5 206, doi: 10.3390/ani5020206.

Grant, R. A., and T. Halliday (2010). Predicting the unpredictable; evidence of pre-seismic anticipatory behaviour in the common toad, J. Zool. 281 263-271, doi: 10.1111/j.1469-7998.2010.00700.x. 
Grant, R. A., T. Halliday, W. P. Balderer, F. Leuenberger, M. Newcomer, G. Cyr, and F. T. Freund (2011). Ground Water Chemistry Changes before Major Earthquakes and Possible Effects on Animals, Int. J. Env. Res. Public Health 8 1936-1956, doi: 10.3390/ijerph8061936.

Griffiths, W. D., and G. A. L. DeCosemo (1994). The assessment of bioaerosols: A critical review, J. Aerosol Sci. 25 1425-1458, doi: 10.1016/0021-8502(94)90218-6.

Harnett, C. (2012). To what extent can animals aid earthquake prediction?.(Review Article), Young Scientists Journal 560.

Hatai, S., and N. Abe (1932). The Responses of the Catfish, Parasilurus Asotus, to Earthquakes, Proc. Imperial Acad. 8 375-378, doi: 10.2183/pjab1912.8.375.

Hayakawa, M. (2013). Possible electromagnetic effects on abnormal animal behavior before an earthquake, Animals 3 19-32, doi: 10.3390/ani3010019.

Hayakawa, M., T. Asano, A. Schekotov, and H. Yamauchi (2016a). A study on the correlation of milk yield of cows with seismicity and ULF magnetic field variations, Open J. Earthquake Res. 05 206-218, doi: 10.4236/ojer.2016.54017.

Hayakawa, M., H. Yamauchi, N. Ohtani, M. Ohta, S. Tosa, T. Asano, A. Schekotov, J. Izutsu, S. M. Potirakis, and K. Eftaxias (2016b). On the precursory abnormal animal behavior and electromagnetic effects for the Kobe earthquake (M 6) on April 12, 2013, Open J. Earthquake Res. 05 165-171, doi: 10.4236/ojer.2016.53013.

Hentig, H. v. (1923). Reactions of animals to changes in physical environment I. Animal and earthquake, J. Comp. Psychol. 61-71.

Heupel, M. R., C. A. Simpfendorfer, and R. E. Hueter (2003). Running before the storm: blacktip sharks respond to falling barometric pressure associated with Tropical Storm Gabrielle, J. Fish Biol. 63 1357-1363, doi: 10.1046/j.1095-8649.2003.00250.x.

Hoenig, S. A. (1979). Aerosol anomalies preceding earthquakes, Nature 279 169-169, doi: 10.1038/279169b0.

Hussain, M., and S. Asif (2012). Signal, animal response and earthquake, J. Theor. Appl. Inform. Tech. 39 218-224.

Ikeya, M. (2004). Earthquakes and animals: from folk legends to science, World Scientific, Singapore, 295.

Ikeya, M., Y. Emoto, H. Asahara, and C. Yamanaka (2004). Air bubble movements and animal behavior as responses to electromagnetic signals before earthquakes: network monitoring of catfish, in EMC'04, http://www.ieice.org, Sendai, 749-752.

Ikeya, M., H. Furuta, N. Kajiwara, and H. Anzai (1996a). Ground electric field effects on rats and sparrows: seismic anomalous animal behaviors (SAABs), Jpn. J. Appl. Phys. 35 4587-4594.

Ikeya, M., T. Komatsu, Y. Kinoshita, K. Teramoto, K. Inoue, M. Gondou, and T. Yamamoto (1997). Pulsed electric field before Kobe and Izu earthquakes from seismically-induced anomalous animal behavior (SAAB), Episodes 20 253-260.

Ikeya, M., T. Matsuda, and C. Yamanaka (1998a). Reproduction of mimosa and clock anomalies before earthquakes: Are they "Alice in the Wonderland syndrome"?, Proceedings of the Japan Academy Series B: Physical \& Biological Sciences 74 60-64.

Ikeya, M., H. Matsumoto, and Q.-H. Huang (1998b). Alignment silkworms as seismic animal anomalous behavior (SAAB) and electromagnetic model of a fault: a theory and laboratory experiment, Acta Seism. Sin. 11 365-374, doi: 10.1007/s11589-998-0045-3.

Ikeya, M., S. Takaki, and D. Takashimizu (1996b). Electric shocks resulting in seismic animal anomalous behaviors (SAABs), J. Phys. Soc. Jpn. 65 710-712.

Ikeya, M., and N. E. Whitehead (2013). Unusual childhood waking as a possible precursor of the 1995 Kobe earthquake, Animals 3 228-237, doi: 10.3390/ani3010228.

Ikeya, M., C. Yamanaka, T. Mattsuda, H. Sasaoka, H. Ochiai, Q. H. Huang, N. Ohtani, T. Komuranani, M. Ohta, Y. Ohno, and T. Nakagawa (2000). Electromagnetic pulses generated by compression of granitic rocks and animal behavior, Episodes 23 262-265.

Jiang, J.-C. (1980). Animal abnormal behavior is an earthquake short-term precursor, Acta Seism. Sin. 2 304-313.

Kario, K., B. S. McEwen, and T. G. Pickering (2003). Disasters and the heart: A review of the effects of earthquakeinduced stress on cardiovascular disease, Hypertens. Res. 26 355-367, doi: 10.1291/hypres.26.355. 
Katsika-Tsigourakou, V. (2012). Comment on the “Int J Environ Res Public Health. 8:1936.”, by R. A. Grant, T. Halliday, W. P. Balderer, F. Leuenberger, M. Newcomer, G. Cyr and F. T. Freund. Int. J. Environ. Res. Public Health, 2011, 8, 1936-1956, Int. J. Env. Res. Public Health 9 2339-2342, doi: 10.3390/ijerph9072339.

Kattnig, D. R., E. W. Evans, V. Déjean, C. A. Dodson, M. I. Wallace, S. R. Mackenzie, C. R. Timmel, and P. J. Hore (2016). Chemical amplification of magnetic field effects relevant to avian magnetoreception, Nat. Chem. 8 384391, doi: 10.1038/nchem.2447.

Kelley, C. M., and M. Garstang (2013). On the possible detection of lightning storms by elephants, Animals 3 349355, doi: 10.3390/ani3020349.

Kelman, I., R. Spence, J. Palmer, M. Petal, and K. Saito (2008). Tourists and disasters: lessons from the 26 December 2004 tsunamis, J. Coast. Conserv. 12 105-113, doi: 10.1007/s11852-008-0029-4.

Kerr, R. A. (1980). Quake Prediction by Animals Gaining Respect, Science 208 695, doi: 10.1126/science.208.4445.695.

Kirschvink, J. L. (2000). Earthquake prediction by animals; evolution and sensory perception, Bull. Seismol. Soc. Am. 90 312-323, doi: 10.1785/0119980114.

Kirschvink, J. L. (2014). Sensory biology: Radio waves zap the biomagnetic compass, Nature 509 296-297, doi: 10.1038/nature13334.

Kirschvink, J. L., M. Winklhofer, and M. M. Walker (2010). Biophysics of magnetic orientation: strengthening the interface between theory and experimental design, J. R. Soc. Interface 7 S179-S191, doi: 10.1098/rsif.2009.0491.focus.

Knuts, E., K. G. Hinzen, S. K. Reamer, and T. Camelbeeck (2017). A Nineteenth-Century National Prussian Macroseismic Questionnaire, Seismol. Res. Lett. 89 191-201, doi: 10.1785/0220170199.

Kopytenko, Y. A., N. I. Komarovskikh, P. M. Voronov, and E. A. Kopytenko (1995). On possible connection of ultrlow-frequency electromagnetic lithosphere emissions with unusual behavior of biological systems before the strong earthquakes (russian), Biofizika 40 1114-1116.

Kraemer, H. C., B. E. Smith, and S. Levine (1976). An animal behaviour model for short term earthquake prediction, in National Earthquake Hazards Reduction Program, Conference I, Abnormal Animal Behavior Prior to Earthquakes I J. F. Evernden (Editor), US Dept. of the Interior Geological Survey, Menlo Park, 231-232.

Krueger, A. P., and E. J. Reed (1976). Biological impact of small air ions, Science 193 1209, doi: 10.1126/science.959834.

Lakshmi, K. R., Y. Nagesh, and M. Veera Krishna (2014). Analysis on Predicting Earthquakes through an Abnormal Behavior of Animals, Int. J. Sci. Eng. Res. 5 845-857.

Lecocq, T., Rapagnani, G., Martin, H., De Vos, F., Hendrickx, M., Van Camp, M., Vanneste, K., Camelbeeck, T. (2009). B-FEARS: The Belgian Felt Earthquake Alert and Report System, Cahiers du Centre Européen de Géodynamique et de Séismologie.

Li, J. (1989). Abnormal behavior of selected animals prior of earthquake, Journal of Beijing Polytechnic University 15 73-75.

Li, J. Z. (2008). Abnormal behaviors of budgerigar and imminent earthquake prediction, Beijing Gongye Daxue Xuebao / Journal of Beijing University of Technology 34 216-219.

Li, J. Z., Z. Q. Bai, W. S. Chen, Y. Q. Xia, Y. R. Liu, and Z. Q. Ren (2003). Strong earthquakes can be predicted: A multidisciplinary method for strong earthquake prediction, Nat. Hazards Earth Syst. Sci. 3 703-712.

Li, Y., Y. Liu, Z. Jiang, J. Guan, G. Yi, S. Cheng, B. Yang, T. Fu, and Z. Wang (2009). Behavioral change related to Wenchuan devastating earthquake in mice, Bioelectromagnetics 30 613-620, doi: 10.1002/bem.20520.

Lighton, J. R., and F. D. Duncan (2005). Shaken, not stirred: a serendipitous study of ants and earthquakes, J. Exp. Biol. 208 3103-7, doi: 10.1242/jeb.01735.

Lindberg, R. G., D. D. Skiles, and P. Hayden (1981). Can animals predict earthquakes? A search for correlations between changes in activity patterns of two fossorial rodents and subsequent seismic events, in Open File Rep. US Geol. Surv., 37.

Liu, J., W. Wei, H. Kuang, J. Z. Tsien, and F. Zhao (2014). Heart Rate and Heart Rate Variability Assessment Identifies Individual Differences in Fear Response Magnitudes to Earthquake, Free Fall, and Air Puff in Mice, PLos One 9 14, doi: 10.1371/journal.pone.0093270. 
Liu, Y. L., H. B. Lillywhite, and M. C. Tu (2010). Sea snakes anticipate tropical cyclone, Mar. Biol. 157 2369-2373, doi: 10.1007/s00227-010-1501-X.

Logan, J. M. (1977). Animal behaviour and earthquake prediction, Nature 265 404-405.

Lott, D. F., B. L. Hart, and M. W. Howell (1981). Retrospective studies of unusual animal behavior as an earthquake predictor, Geophys. Res. Lett. 8 1203-1206, doi: 10.1029/GL008i012p01203.

Lott, D. F., B. L. Hart, K. L. Verosub, and M. W. Howell (1979). Is unusual animal behavior observed before earthquakes? Yes and no, Geophys. Res. Lett. 6 685-687, doi: 10.1029/GL006i009p00685.

Lowry, M. A. (1983). Can animals help earthquake predictors?, New Zeal. Vet. J. 31 35-39, doi: 10.1080/00480169.1983.34956.

Lutz, C. W. (1921). Erdbeben in Bayern 1908/20, Sitzungsberichte der Bayerischen Akademie der Wissenschaften 1921 81-165.

Ma, Y., and Y. Chen (2013). A study on the characteristics of anomalies and their dynamic relationship before the April 14, 2010 Ms 7.1 Yushu earthquake, Earthquake Res. China 27 39-51.

McClellan, P. H. (1980). Preearthquake animal behavior; a closer look for alternative causes, Geophys. Res. Lett. 7 333-336, doi: 10.1029/GL007i005p00333.

Medici, R. G., A. H. Frey, and D. Frey (1985). Response facilitation: Implications for perceptual theory, psychotherapy, neurophysiology, and earthquake prediction, Int. J. Neurosci. 26 47-52, doi: 10.3109/00207458508985602.

Molchanov, O. (2008). Social tension as precursor of large damaging earthquake: legend or reality?, Nat. Hazards Earth Syst. Sci. 8 1259-1265, doi: 10.5194/nhess-8-1259-2008.

Montenegro, M. A., H. Palomino, and H. M. Palomino (1995). The influence of earthquake-induced stress on human facial clefting and its simulation in mice, Arch. Oral Biol. 40 33-37.

Nienaber, J. A., G. L. Hahn, and R. A. Eigenberg (1999). Quantifying livestock responses for heat stress management: a review, Int. J. Biometeorol. 42 183-188, doi: 10.1007/s004840050103.

Nikonov, A. A. (1992). Abnormal animal behavior as a precursor of the 7 December 1988 Spitak, Armenia, earthquake, Nat. Hazards 6 1-10.

Nishimura, T., H. Okano, H. Tada, E. Nishimura, K. Sugimoto, K. Mohri, and M. Fukushima (2010). Lizards respond to an extremely low-frequency electromagnetic field, J. Exp. Biol. 213 1985-1990, doi: 10.1242/jeb.031609.

Nunn, P. (2014). Lashed by sharks, pelted by demons, drowned for apostasy: the value of myths that explain geohazards in the Asia-Pacific region, Asian Geogr. 31 59-82, doi: 10.1080/10225706.2013.870080.

Omori, F. (1923). Pheasant as Seismoscope, Bull. Jap. Imp. Earthq. Investig. Comm. 11 1-5.

Otis, L. S., and W. H. Kautz (1980). Biological premonitors of earthquakes; a validation study, in Open File Rep. US Geol. Surv., 80-1152.

Otis, L. S., W. H. Kautz, S. Geological Survey . Office of Earthquake, and S. R. I. International (1985). Biological Premonitors of Earthquakes: A Validation Study : Final Report, SRI International.

Panagopoulos, D. J., A. Karabarbounis, and L. H. Margaritis (2002). Mechanism for action of electromagnetic fields on cells, Biochem. Biophys. Res. Comm. 298 95-102, doi: 10.1016/s0006-291x(02)02393-8.

Panagopoulos, D. J., N. Messini, A. Karabarbounis, A. L. Philippetis, and L. H. Margaritis (2000). A Mechanism for Action of Oscillating Electric Fields on Cells, Biochem. Biophys. Res. Comm. 272 634-640, doi: http://dx.doi.org/10.1006/bbrc.2000.2746.

Petrazzi, L., R. Striuli, L. Polidoro, G. Properzi, R. Casale, P. Pasqualetti, G. Desideri, C. Ferri, and G. Parati (2010). Changes in 24-Hour Ambulatory Blood Pressure Monitoring during the 2009 Earthquake at L'Aquila, Am. J. Med. 123 E1-E3, doi: 10.1016/j.amjmed.2010.01.038.

Philippetis, A. L. (2009). Electromagnetic signals before rupture and their possible interconnection with bioeffects, Mod. Phys. Lett. B 23 1431-1436.

Reasenberg, P. (1978). Unusual animal behaviour before earthquakes, Earthquake Information Bulletin (USGS) 10 42-50.

Rikitake, T. (1978). Biosystem behaviour as an earthquake precursor, Tectonophysics 51 1-20, doi: 10.1016/00401951(78)90048-3. 
Rikitake, T. (2001). Predictions and Precursors of Major Earthquakes: The Science of Macro-scopic Anomalous Phenomena, Tokyo, 198+xii.

Rikitake, T., N. Oshiman, and M. Hayashi (1993). Macro-anomaly and its application to earthquake prediction, Tectonophysics 222 93-106, doi: 10.1016/0040-1951(93)90192-M.

Ritz, T. (2011). Quantum effects in biology: Bird navigation, Procedia Chemistry 3 262-275, doi: 10.1016/j.proche.2011.08.034.

Ritz, T., T. Yoshii, C. Foerster, and M. Ahmad (2010). Cryptochrome, Communicative \& Integrative Biology $324-$ 27, doi: 10.4161/cib.3.1.9865.

Sakakibara, H., M. Torii Yasuda, and K. Shimoi (2016). Effects of environmental and social stressors on biological rhythms, J. Sports Med. Phys. Fitness 5 143-152, doi: 10.7600/jpfsm.5.143.

Sbarra, P., P. Tosi, and V. De Rubeis (2009). Web-based macroseismic survey in Italy: method validation and results, Nat. Hazards 54 563-581, doi: 10.1007/s11069-009-9488-7.

Schaal, R. B. (1988). An evaluation of the animal-behavior theory for earthquake prediction, Calif. Geol. $4141-45$.

Schnytzer, A., and Y. Schnytzer (2011). Animal modeling of earthquakes and prediction markets, in Working Papers, Bar-Ilan University, Department of Economics.

Sciarra, A., F. Quattrocchi, B. Cantucci, and F. Mazzarini (2014). Earth is speaking: listen her! On-line questionnaire about anomalous geological and biological phenomena, in EGU2014, Vienna.

Segnalini, M., U. Bernabucci, A. Vitali, A. Nardone, and N. Lacetera (2013). Temperature humidity index scenarios in the Mediterranean basin, Int. J. Biometeorol. 57 451-458, doi: 10.1007/s00484-012-0571-5.

Shi, Z. (1986). On abnormal commotion of animals before earthquakes, Earthquake (Beijing) 5 26-30.

Sidorin, A. Y. (2003). Search for earthquake precursors in multidisciplinary data monitoring of geophysical and biological parameters, Nat. Hazards Earth Syst. Sci. 3 153-158.

Singh, A. K., and N. Singh (2012). Biosensor and its applications, scientificreports 1 387, doi: 10.4172/scientificreports.387.

Smits, G. (2006). Shaking Up Japan: Edo Society and the 1855 Catfish Picture Prints, J. Soc. Hist. 39 1045-1078, doi: 10.1353/jsh.2006.0057.

Smits, G. (2014). Seismic Japan: The long history and continuing legacy of the Ansei Edo earthquake, University of Hawaii Press, 263.

Snarr, K. A. (2005). Seismic activity response as observed in mantled howlers (Alouatta palliata), Cuero y Salado Wildlife Refuge, Honduras, Primates 46 281-285, doi: 10.1007/s10329-005-0151-y.

Stierman, D. J. (1980). Earthquake sounds and animal cues; some field observations, Bull. Seismol. Soc. Am. 70 639643.

Straka, W., R. Assef, R. Faber, and R. Ferasyi (2015). Integrated study of geophysical and biological anomalies before earthquakes (seismic and non-seismic), in Austria and Indonesia, in EGU2015, Vienna.

Straser, V. (2013). A potential relationship between aimal behavior and pre-seismic signals in the North Western Apennines (Italy), New Concepts in Global Tectonics Journal 1 11-16.

Suyehiro, K. (1934). Some observations on the unusual behaviour of fishes prior to an earthquake.

Tan, C. E., H. J. Li, X. G. Zhang, H. Zhang, P. Y. Han, Q. An, W. J. Ding, and M. Q. Wang (2009). The impact of the Wenchuan earthquake on birth outcomes, PLos One 4 e8200, doi: 10.1371/journal.pone.0008200.

Tomoda, Y. (1998). Day to day variation in catch of fish and seismic activity, Proc. Japan Acad. 74 179-184.

Tong, W. K. (1988). Abnormal animal behaviour and the prediction of earthquakes, in Department of Earth Sciences, Northeastern Illinois University, 14.

Tributsch, H. (1978a). Do aerosol anomalies precede earthquakes?, Nature 276 606-608, doi: 10.1038/276606a0.

Tributsch, H. (1978b). Wenn die Schlangen erwachen: mysteriöse Erdbebenvorzeichen; endlich ernstgenommene Naturphänomene führen zu einem Frühwarnsystem, Deutsche Verlags-Anstalt, 272.

Tributsch, H. (1984). When the snakes awake - animals and earthquake prediction, MIT Press Cambridge, Mass., 248.

Tributsch, H. (2005). The bionic anticipation of natural disasters, JBE 2 123-144. 
Tributsch, H. (2013a). Bio-mimetics of disaster anticipation-learning experience and key-challenges, Animals 3 274299, doi: 10.3390/ani3010274.

Tributsch, H. (2013b). The escaping “pneuma” - gas of ancient earthquake concepts in relation to animal, atmospheric and thermal precursors, in EGU2013, Vienna.

Tweddle, D., and R. Crossley (1991). Effects of an earthquake on demersal cichlid fishes of southern Lake Malawi, J. Fish Biol. 38 305-308, doi: 10.1111/j.1095-8649.1991.tb03116.x.

van Noten, K., Lecocq, T., Sira, C., Hinzen, K.-G., Camelbeeck, T. (2017). Path and site effects deduced from merged transfrontier internet macroseismic data of two recent M4 earthquakes in northwest Europe using a grid cell approach, Solid Earth 8 453-477, doi: 10.5194/se-8-453-2017.

Vitaliano, D. B. (2007). Geomythology: geological origins of myths and legends in Myth and Geology L. Piccardi and W. B. Masse (Editors), The Geological Society of London, 1-7.

Weaver, J. C., T. E. Vaughan, and R. D. Astumian (2000). Biological sensing of small field differences by magnetically sensitive chemical reactions, Nature 405 707-709, doi: 10.1038/35015128.

Whitehead, N. E., and Ü. Ulusoy (2013). Macroscopic anomalies before the September $2010 \mathrm{M=7.1}$ earthquake in Christchurch, New Zealand, Nat. Hazards Earth Syst. Sci. 13 167-176, doi: 10.5194/nhess-13-167-2013.

Whitehead, N. E., U. Ulusoy, H. Asahara, and M. Ikeya (2004). Are any public-reported earthquake precursors valid?, Nat. Hazards Earth Syst. Sci. 4 463-468.

Wikramanayake, E., P. Fernando, and P. Leimgruber (2006). Behavioral response of satellite-collared elephants to the tsunami in southern Sri Lanka, Biotropica 38 775-777, doi: 10.1111/j.1744-7429.2006.00199.x.

$\mathrm{Xu}, \mathrm{M}$., and J. Jiang (1989). A study on the memory response of mice to earthquake premonitory geosound, Acta Seism. Sin. 2 562-571.

Yamauchi, H., M. Hayakawa, T. Asano, N. Ohtani, and M. Ohta (2017). Statistical Evaluations of Variations in Dairy Cows' Milk Yields as a Precursor of Earthquakes, Animals 7 doi: 10.3390/ani7030019.

Yamauchi, H., H. Uchiyama, N. Ohtani, and M. Ohta (2014). Unusual animal behavior preceding the 2011 earthquake off the pacific coast of Tohoku, Japan: A way to predict the approach of large earthquakes, Animals 4 131-145, doi: 10.3390/ani4020131.

Yanai, S., Y. Semba, and S. Endo (2012). Remarkable Changes in Behavior and Physiology of Laboratory Mice after the Massive 2011 Tohoku Earthquake in Japan, PLos One 7 8, doi: 10.1371/journal.pone.0044475.

Yokoi, S., M. Ikeya, T. Yagi, and K. Nagai (2003). Mouse circadian rhythm before the Kobe earthquake in 1995 , Bioelectromagnetics 24 289-291, doi: 10.1002/bem.10108.

Yosef, R. (1997). Reactions of Grey Herons (Ardea cinerea) to seismic tremors, Journal für Ornithologie $138543-$ 546.

Yosef, R. (2010). Reactions of birds to an earthquake, Bird Study 44 123-124, doi: 10.1080/00063659709461047. 